\title{
¿Por quién doblan las campanas del Derecho? Sobre la exclusión jurídica y sociopolítica de los inmigrantes indocumentados
}

\author{
For Whom the Law Tolls? On the Legal and Socio- \\ Political Exclusion of Undocumented Immigrants
}

Matija Žgur*

"In any civilized country he who has no passport is nobody. He does not exist for us or for anybody else. We can do whatever we want to."

(B. Traven, The Death Ship, 1934, p. 23)

"No man is an island, entire of itself; every man is a piece of the continent, a part of the main. If a clod be washed away by the sea, Europe is the less, as well as if a promontory were, as well as if a manor of thy friend's or of thine own were: any man's death diminishes me, because I am involved in mankind, and therefore never send to know for whom the bell tolls; it tolls for thee."

(J. Donne, Meditation XVII, 1623)

Recepción: 13/12/2018

Evaluación: 16/05/2019

Aceptación final: 14/07/2019

Resumen: Este artículo toma como punto de partida el libro de Robert Barsky Undocumented Immigrants in an Era of Arbitrary Law. The Flight and the Plight of People Deemed "Illegal" (Routledge, 2016). En particular, analiza dos argumentos sostenidos en el libro: primero, que el carácter

Investigador Postdoctoral, Facultad de Derecho, Università di Roma Tre, Italia; co-director de Revus - journal for constitutional theory and philosophy of law. Correo electrónico: matija.zgur@uniroma3.it. Una traducción revisada (al esloveno) de este artículo será publicada en: Pravnik - revija za pravno teorijo in prakso (2019) 3-4. Quisiera agradecer a Mojca M. Plesničar y Aleš Bučar Ručman por sus comentarios a este texto y a Milton Jair Rocha Mendoza por su arduo trabajo de traducción. 
Matija Žgur

irregular (ilegal) del estatus jurídico de los inmigrantes indocumentados los expone a la arbitrariedad en la aplicación del derecho por parte de los funcionarios de la "primera línea". En segundo lugar, esa arbitrariedad, como mecanismo de exclusión jurídica, suele complementarse y reforzarse con mecanismos de exclusión sociopolítica. El autor comienza analizando estos mecanismos de exclusión y, en la última parte del artículo, analiza el caso de los Borrados en Eslovenia, poniendo a prueba las tesis y la metodología propuestas en la parte precedente.

Palabras clave: inmigrantes indocumentados, arbitrariedad, exclusión jurídica, exclusión social, Otredad

\begin{abstract}
This article takes as its starting point Robert Barsky's book Undocumented Immigrants in an Era of Arbitrary Law. The Flight and the Plight of People Deemed "Illegal" (Routledge, 2016). In particular, it discusses two arguments sustained therein: first, that the irregular (illegal character of the undocumented immigrants' legal status exposes them to arbitrariness in the application of the law by the host county's "frontline" legal officials. Secondly, that arbitrariness as a mechanism of legal exclusion is typically supplemented and reinforced by mechanisms of socio-political exclusion. The author first analyses these exclusionary mechanisms, while in the latter part of the article, he analyses the case of the Erased in Slovenia, in order to test the theses and the methodology proposed in the previous part.

Keywords: undocumented immigrants, arbitrariness, legal exclusion, social exclusion, Othering
\end{abstract}

\title{
1. Detenciones policiales, "bad hombres" y buenos desayunos
}

Si en mi país un policía me detiene mientras manejo un automóvil, sería razonable para mí suponer que ello se debe a que he cometido alguna violación de tránsito, por ejemplo, el exceso de velocidad. En tal caso, el oficial de policía probablemente requerirá mi licencia para conducir y me informará sobre la supuesta violación. Antes de emitir la multa, me informará también acerca de los derechos y obligaciones que tengo durante el procedimiento (por ejemplo, el derecho a rehusar una prueba de alcoholímetro, la fecha 
¿Por quién doblan las campanas del Derecho? Sobre la exclusión jurídica...

límite para pagar la multa, el derecho a apelar la decisión, etc.); omitir darme esa información constituiría una violación de mis derechos fundamentales y podría resultar en la anulación de la sanción. Con toda probabilidad, una vez hecho eso, me devolverá mis documentos, y ese sería el final del asunto.

Si lo mismo ocurriera a una persona de piel más oscura en algún país extranjero - digamos a un mexicano en Estados Unidos, a un gambiano en Francia, o a un indonesio en Australia - tal encuentro se desarrollaría, con buena probabilidad, de una manera diferente. En Estados Unidos, por ejemplo, no es poco común para los agentes de policía detener a personas sin otra razón que no sea "driving while Mexican". Debido a que hay un gran número de personas provenientes de América latina residiendo en Estados Unidos sin documentos apropiados (en otras palabras, ilegalmente), las posibilidades de que el individuo en cuestión sea un " $b a d$ hombre” son relativamente altas ${ }^{2}$. Sobre la base de esta presuposición, el oficial de policía puede actuar de diversas formas. Por ejemplo, dado que conducir un vehículo sin la debida licencia para ello es en sí mismo una transgresión a la ley, el policía podría sobre esa única base citar a la persona. Pero el oficial puede además desear inspeccionar el automóvil

1 Sobre este fenómeno en el contexto de Estados Unidos, véase: Romero M., "Racial Profiling and Immigration Law Enforcement: Rounding Up of Usual Suspects in the Latino Community", Critical Sociology, 32, 2-3, 2006, pp. 447-473; Mucchetti, A., "Driving while Brown: A Proposal for Ending Racial Profiling in Emerging Latino Communities", Harvard Latino Law Review, 8, 2005, pp. 1-32. En general, sobre los perfiles raciales en este campo, véase Baumgartner, F., Epp, D., Shoub, K., Suspect Citizens. What 20 Million Traffic Stops Tell Us about Policing and Race, Cambridge, Cambridge University Press, 2018; Johnson, K., "The Case Against Race Profiling in Immigration Enforcement", Washington University Law Quarterly, 78, 3, 2000, pp. 675-736; Knowles, J., Persico, N., Todd, pág., "Racial Bias in Motor Vehicle Searches: Theory and Evidence”, Journal of Political Economy, 109, 1, 2001, pp. 203-229. Sobre análisis de perfiles raciales en relación con inspecciones policiales en el contexto europeo, véase: Goris, I., Jobard, F., Lévy R., Profiling Minorities: A Study of Stopand-Search Practices in Paris, New York, Open Society Institute, 2010 (for Paris, France); Miller, J. et al., "Racism and Police Stops. Adapting US and British Debates to Continental Europe”, European Journal of Criminology, 5, 2, 2008, pp. 161-191 (for Bulgaria, Hungary and Spain). [NT: resulta difícil traducir la expression "driving while Mexican", por lo que optamos por mantenerla en inglés. La expresión pretende capturar la idea de que "conducir" y "ser mexicano" son las únicas razones por las que la policía detiene a algunas personas]

2 Este término peyorativo para designar a los latinoamericanos ha sido repetidamente empleado por el actual presidente de EEUU Donald Trump durante su campaña presidencial. 
en busca de narcóticos o armas - no necesariamente actuando conforme a una sospecha en concreto, sino conforme a una creencia generalizada según la cual todos los mexicanos son traficantes de drogas y tienden a portar armas de fuego sin registro. Para hacer esto, el oficial necesita una orden de cateo o el consentimiento de la persona, sin embargo, dada su ya vulnerable posición, es poco probable que la persona ejerza su derecho a rechazar la revisión. Por supuesto, puede suceder que el oficial proceda con la revisión sin siquiera dar a la persona información sobre sus derechos. Es más, aun cuando le diera esa información, es muy probable que la persona no entienda al oficial debido a un escaso conocimiento del idioma inglés. Y si el oficial encuentra narcóticos, por más reducida que sea la cantidad hallada, la persona en cuestión será arrestada y enfrentará cargos por delitos graves. En cualquier punto de este proceso, el oficial de policía puede además optar por pedir información sobre el estado migratorio de la persona y si descubre que está de manera ilegal en el país, casi con toda certeza será encarcelada y finalmente deportada.

\section{La difícil situación de los inmigrantes indocumentados trasciende las fronteras (científicas)}

Tales incidentes no se producen únicamente en Estados Unidos, Australia o cualquier otro Estado en particular. Al contrario, lo que yo sostengo es que son fenómenos comunes en países "Occidentales". En este artículo, afirmo que tales encuentros entre inmigrantes indocumentados y funcionarios de la "primera línea" del Estado anfitrión, comparten (al menos) las siguientes características ${ }^{3}$ : (i) Un conjunto particular de circunstancias legales que, en parte, surgen en virtud de los confines espaciales en que tales encuentros ocurren y que otorgan a los funcionarios un alto margen de discreción para tomar decisiones; (ii) la específica condición jurídica de

3 Una nota terminológica: (1) A lo largo de este artículo utilizo el término "indocumentado" en lugar de "ilegal" por dos razones principales. Primero, porque el adjetivo "ilegal" es empleado típicamente de manera peyorativa con el fin de promover estereotipos negativos sobre los inmigrantes indocumentados, definiéndolos como criminales. Segundo, porque la condición de indocumentado es una situación factual (que incluye, por un lado, no tener 
¿Por quién doblan las campanas del Derecho? Sobre la exclusión jurídica...

los inmigrantes indocumentados que los hace particularmente vulnerables y los expone a abusos por parte de los funcionarios; (iii) el hecho de que las decisiones de los funcionarios (detener un vehículo, levantar cargos por delitos relacionados con drogas e inmigración, etc.) no resulten tanto de lo que exigen las normas jurídicas, sino que dependan de la calidad del desayuno que cada funcionario tomó por la mañana ${ }^{4}$, lo que el presidente Donald Trump acaba de decir sobre los mexicanos en Twitter, o alguna otra razón igualmente sospechosa.

Como ciudadanos pertenecientes a democracias consolidadas, no estamos acostumbrados a pensar en el derecho y en sus funcionarios de esta manera. Cuando interactuamos con agentes del gobierno, confiamos en que tienen bases razonables para detenernos a mitad del camino; en que, al hacerlo así, ellos se apegan a procedimientos predeterminados y a estándares estrictos para rastrear evidencias, y en que tenemos un derecho efectivo de apelar sus decisiones si sentimos que nuestros derechos han sido violados. En otras palabras: tenemos expectativas razonables acerca de que sus acciones estarán basadas exclusivamente en prescripciones legales válidas. Aun así, parece que el Estado de derecho, tan obvio para nosotros como ciudadanos, no es sino una ilusión para los inmigrantes indocumentados que viven en nuestra sociedad. Parece que, en lugar de claridad, predictibilidad y certeza, el contacto que ellos tienen con los funcionarios de la "primera línea" se caracteriza por la arbitrariedad y por una completa impredecibilidad de las consecuencias resultantes de estos encuentros.

Las características de los encuentros en la primera línea entre inmigrantes indocumentados y funcionarios del país anfitrión y, en particular, la impredecibilidad que experimentan los primeros, conforman el tema

documentos de identidad ni de residencia en absoluto y, por otro lado, no tener una identidad ni documentos de residencia válidos) mientras que la ilegalidad es, como sostengo aquí, un estado contingente producido por el derecho. (2) Por funcionarios de la "primera línea" (frontline) me refiero a los funcionarios de un país encargados de aplicar (enforce), en situaciones de contacto directo con los destinatarios, normas jurídicas referidas a los inmigrantes indocumentados. Estos funcionarios incluyen, por ejemplo, oficiales de policía, guardias fronterizos, agentes de inmigración y aduanas, etc.

4 Jerome Frank, una figura que lidera el realismo juridico de Estados Unidos, es conocido por haber dicho "La justicia es lo que el juez haya comido en el desayuno". Véase, además Tuzet, G., "A Short Note on Digestive Realism”, Revus, 25, 2015, pp. 11-14. 
Matija Žgur

central del libro de Robert Barsky Undocumented Immigrants in an Era of Arbitrary Law. The Flight and the Plight of People Deemed "Illegal". Como Barsky mismo lo pone: "este libro describe los altos niveles de impredecibilidad, discrecionalidad, volubilidad y arbitrariedad que [...] dominan en todos los niveles la interacción entre migrantes indocumentados y funcionarios de los países anfitriones alrededor de todo el mundo" 5 .

La inmigración ilegal ${ }^{6}$ es un tema sensible en el discurso académico y político, particularmente en años recientes. Los académicos de distintos perfiles, incluyendo abogados, politólogos, sociólogos, antropólogos, historiadores y economistas discuten fervientemente los aspectos de este fenómeno que se relacionan más de cerca con sus respectivos campos de estudio. Barsky, por el contrario, trasciende los estrechos confines disciplinarios del derecho y otras ciencias sociales al proporcionar una mirada profunda de la huida y el sufrimiento (the flight and the plight) de los inmigrantes indocumentados, que combina trabajo de campo (testimonios provenientes de defensores públicos, de funcionarios encargados de aplicar la ley, de traductores y de los migrantes mismos) con un amplio análisis de literatura académica que abarca desde el derecho, la sociología y los derechos humanos hasta la interpretación y la traducción de estudios, análisis crítico del discurso y otros. Si bien el método de Barsky es predominantemente descriptivo, no muestra timidez para criticar las regulaciones y las prácticas actuales respecto de los inmigrantes indocumentados. Además, también aboga abiertamente por un trato más humano para estos individuos en todos los niveles y termina pidiendo un sistema de fronteras abiertas ${ }^{7}$.

Este acercamiento interdisciplinario hace que el libro de Barsky sea refrescante para todos aquellos que son conscientes de que un fenómeno complejo como la migración no debe ser tratado de manera unidimensional. Con este mismo espíritu, se puede argumentar que el elemento más

5 Barsky, R., Undocumented Immigrants in an Era of Arbitrary Law. The Flight and the Plight of People Deemed "Illegal", Oxon-London, Routledge, 2016, p. x.

6 Este concepto incluye tanto personas que cruzan la frontera de un modo que es considerado ilegal por el ordenamiento jurídico de un país en particular, como personas cuya residencia en un país se vuelve ilegal (debido, por ejemplo, a permanecer más tiempo del que la visa lo permite), aun cuando su ingreso había sido legal. 
¿Por quién doblan las campanas del Derecho? Sobre la exclusión jurídica...

interesante e innovador del libro de Barsky es el análisis de las dificultades que enfrentan los inmigrantes indocumentados a través de la perspectiva de los expertos en lenguaje - los traductores e intérpretes que auxilian a los inmigrantes en varias etapas de la interacción que tienen con los funcionarios del país anfitrión. Concentrarse en este punto de vista en particular permite al autor resaltar el impacto que las barreras de comunicación tienen sobre la posición jurídica de los inmigrantes indocumentados. Mientras que este tema es poco discutido en la literatura jurídica, para Barsky el lenguaje está en el núcleo del fenómeno de la inmigración-cruzar una frontera, dice él, es "un acto lingüístico tanto como físico"8. Más importante, le sirve como puerta de entrada al debate sobre los problemas de exclusión social que enfrentan los inmigrantes en las sociedades anfitrionas. A la luz de lo que observamos en las noticias de cada día, entrelazar las perspectivas jurídica y lingüística parece totalmente justificado: los debates públicos en países que lidian con una inmigración creciente están saturados con lenguaje xenófobo y de alarmismo contra los inmigrantes. A su vez, a través de su poder para movilizar la opinión pública, estos debates parecen ejercer una gran influencia tanto en el contenido de las políticas de inmigración como, en última instancia, en las acciones de los funcionarios.

Si bien la narrativa del libro no está adherida a ninguna disciplina científica en particular, los asuntos tratados en él y el enfoque que el autor tiene de estos deberían resultar de interés y relevancia para una amplia variedad de lectores expertos — teóricos del derecho incluidos-. Estos últimos, en particular, deberían tomar con seriedad el reto "desde la primera línea" planteado por el análisis de Barsky sobre el modus operandi del derecho con respecto a los inmigrantes indocumentados. Los teóricos del derecho harían bien en otorgar mayor espacio al análisis de la práctica jurídica en sus escritos - que vayan más allá de las esporádicas incursiones en la jurisprudencia de los tribunales de última instancia. Si bien es cierto que conocemos bastante bien cómo los jueces entienden e interpretan la ley ${ }^{9}$,

8 Ibidem, p. 36.

9 La literatura sobre este tema es vasta e imposible de resumir. Algunas de las obras contemporáneas más influyentes son: MacCormick N., Rhetoric and the Rule of Law. A Theory of Legal Reasoning, Oxford, Oxford University Press, 2005; Dworkin, R., Justice in Robes, Cambridge (Mass.), Harvard University Press, 2006, Alexy, R., A Theory of Legal Argumen- 
Matija Žgur

también es cierto que se ha escrito muy poco acerca del mismo punto, pero respecto de los funcionarios encargados de aplicar la ley y de otros "burócratas de la calle"10. Considerando que la vida de personas comunes se ve, en promedio, mayormente afectada por estos últimos que por los jueces, este déficit de conocimiento es injustificable. De esta manera, el enfoque de Barsky sobre las realidades de la aplicación cotidiana de la ley constituye una contribución bienvenida para una mejor comprensión de "el derecho en acción" y su relación con "el derecho en los libros".

Este artículo no es una reseña detallada del libro de Barsky —ello requeriría bastante espacio y experticia en una variedad de temas que yo no poseo-. Más bien, pretende imitar el enfoque de Barsky al combinar un análisis teórico jurídico de un grupo escogido de conceptos y fenómenos jurídicos, con un estudio orientado al aspecto sociológico de las prácticas lingüísticas establecidas, en referencia a los inmigrantes indocumentados. Por lo tanto, el resto de este artículo se concentra en analizar dos argumentos sostenidos por el autor con respecto a la condición jurídica y social de los inmigrantes indocumentados en los países de acogida que parecen ser particularmente relevantes para el derecho y la teoría jurídica: (1) que la "ilegalidad" de los inmigrantes indocumentados los expone a la arbitrariedad en la aplicación de la ley por parte de los funcionarios del país anfitrión, en particular de los que están en la primera línea; (2) que la arbitrariedad (como mecanismo de exclusión jurídica) suele complementarse y reforzarse con de mecanismos de exclusión sociopolítica. El propósito principal de este artículo es entonces examinar las características de estos mecanismos de exclusión y su interacción mutua ${ }^{11}$. También se discuten las

tation. The Theory of Rational Discourse as Theory of Legal Justification, Oxford, Oxford University Press, 2009 (1989); Schauer, F., Thinking Like a Lawyer. A New Introduction to Legal Reasoning, Cambridge (Mass.), Harvard University Press, 2009.

${ }^{10}$ Sobre este tema, véase la obra pionera: Lipsky, M., Street-level Bureaucracy. Dilemmas of the Individual in Public Services, New York, Russell Sage Foundation, 2010 (1970); más recientemente, Zacka, B., When the State Meets the Street. Public Service and Moral Agency, Cambridge (Mass.)-London, The Belknap Press of Harvard University Press, 2017.

11 "Exclusión" se entiende aquí en un sentido amplio, no solo como una exclusión física del territorio de un país anfitrión sino además como una limitación, modificación o privación injustificada (ilegítima, ilegal) de ciertos derechos y estatutos socio-juridicos. Sobre estos tres modelos de exclusión - legal, político y social— véase Mindus, Cittadini e no. Forme 
¿Por quién doblan las campanas del Derecho? Sobre la exclusión jurídica...

consecuencias que estos procesos de exclusión tienen en la vida cotidiana de los inmigrantes indocumentados.

El resto de este artículo está dividido en tres partes. La sección siguiente (3.) es la central y allí examino los dos argumentos arriba mencionados sobre los mecanismos de exclusión jurídica y sociopolítica de inmigrantes indocumentados. Luego (4.), me apoyaré en el caso de "los Borrados" (Erased) para probar la tesis y el método analítico propuesto en la sección anterior. Concluyo (5.) argumentando que la creación de la "ilegalidad" de los inmigrantes indocumentados (en un sentido más amplio) es un fenómeno jurídico y sociopolítico complejo.

\section{La exclusión de los inmigrantes indocumentados a través del derecho y el lenguaje}

Los dos argumentos sobre la exclusión de inmigrantes indocumentados se basan en premisas que contienen la idea subyacente de que la causa principal de la precariedad legal y la vulnerabilidad social ${ }^{12}$ de estos individuos es que su mera presencia en el territorio de un determinado país es considerada ilegal. Incluso una revisión superficial de las dificultades que experimentan estas personas en sus vidas cotidianas parece justificar la tesis según la cual dentro del conjunto de estatus jurídicos que determinan la condición legal de un individuo, la ilegalidad de su residencia asume,

e funzioni dell'inclusione e dell'esclusione, Firenze, Firenze University Press, 2014. Véase también la traducción al español: Hacia una teoría funcionalista de la ciudadanía, Madrid, Marcial Pons, 2019.

${ }^{12}$ La vulnerabilidad de los inmigrantes indocumentados es específicamente situacional y disposicional. Véase Mackenzie, C., Rogers, W. and Dodds, S., "Introduction: What Is Vulnerability and Why Does It Matter for Moral Theory?", en Rogers, W., Mackenzie, C. and Dodds, S. (eds.), Vulnerability. New Essays in Ethics and Feminists Philosophy, Oxford, Oxford University Press, 2014, pp. 1-29. Para más sobre el tema de la vulnerabilidad del inmigrante véase Labman, S., At Law's Border: Unsettling Refugee Resettlement, $\mathrm{PhD}$ Thesis, University of British Columbia, (defended on 15 November 2012). Específicamente sobre la diferencia entre precariedad y vulnerabilidad, véase Atak, I., Nakache, D., Guild, E. and Crépeau, F., "Migrants in vulnerable situations and the Global Compact for Safe Orderly and Regular Migration”, Legal Studies Research Paper No. 273/2018, Queen Mary University of London, School of Law, 2018. 
Matija Žgur

de facto, un papel dominante de estatus supralegal, con el poder de predeterminar todas las interacciones jurídicas futuras de los inmigrantes ${ }^{13}$. De hecho, este estatus impregna de tal manera la condición de los inmigrantes indocumentados que a menudo se dice que ellos mismos son ilegales - como si se tratara de alguna característica autónoma y esencial de su $\operatorname{ser}^{14}$. Sin embargo, tales procesos de transformación no son exclusivos de los inmigrantes indocumentados ni son un desarrollo particularmente novedoso en la historia jurídica ${ }^{15}$ - . Basta pensar en la institución de la esclavitud -el tratamiento de los seres humanos como posesiones personales - para comprender que la ley, efectivamente, tiene la tendencia y el poder de distorsionar la realidad al imponer en el mundo (empírico) sus categorías y entidades artificiales ${ }^{16}$. Sin embargo, la superposición de un estatus jurídico sobre toda la esfera jurídica y social de un individuo o un

${ }^{13}$ Como se ha dicho, este artículo se enfoca en la exclusión legal y sociopolítica de los inmigrantes indocumentados y defiende la tesis según la cual es la ilegalidad en su Estado de residencia lo que determina principalmente la naturaleza del tratamiento que reciben a manos de los funcionarios de la primera línea pertenecientes al país anfitrión. Sin embargo, esta posición no niega que problemas similares a los que se presentan aquí puedan afectar a otros grupos de inmigrantes, en particular a aquellos que buscan asilo y refugio, o incluso a los extranjeros que residen legalmente en un país determinado. Si esto es así, uno podría afirmar que tal vez no sea el hecho de no poseer documentos lo que hace que los inmigrantes sean tan vulnerables a la aplicación arbitraria de la ley, sino más bien alguna otra característica, como su condición de extranjero o incluso su aspecto de extranjero. Aquí no puedo confirmar ni descartar esta objeción. En cualquier caso, la relación entre las diferentes características de los inmigrantes y la forma en que afectan a las acciones de los funcionarios debería estudiarse con más cuidado en el futuro.

${ }^{14}$ A la luz de este entendimiento social difuso respecto a los inmigrantes indocumentados, enfatizo que la "ilegalidad" de los inmigrantes indocumentados no es una condición natural o una característica pre-jurídica. Más bien, esta y otras “ilegalidades" están "constituidas y se rigen por la ley - directa y explícitamente en una manera que se supone es más o menos definitiva [...] y con un grado considerable de deliberación calculada”. (De Genova, N., "Migrant 'Illegality' and Deportability in Everyday Life", Annual Review of Anthropology, 31, 2002, p. 424).

15 Sobre la historia del concepto de estatus jurídico, véase Allen, C.K., "Status and Capacity", Law Quarterly Review, CLXXXIII, 1930, pp. 277-310; Graveson, R.H., Status in the Common Law, London, University of London (Athlone Press), 1953; Maine, H.S., Ancient Law, New York, Henry Holt and Co., 1906, cap. V; Salmond, J., Jurisprudence (4 $4^{\text {th }}$ ed.), London, Stevens \& Haynes, 1913, cap., XV.

16 Como señala Dayan: "Este poder transformador otorga a la ley una realidad que se opone a la lógica, y las ficciones más fantásticas son puestas en marcha como si fueran la cosa más 
¿Por quién doblan las campanas del Derecho? Sobre la exclusión jurídica...

grupo de individuos no puede lograrse únicamente a través de instrumentos exclusivamente jurídicos. Ya sea el convertir a un individuo negro en un "esclavo", o a un convicto en un individuo "civilmente muerto", o a una mujer en una "esposa legalmente incapaz" son transformaciones profundas e integrales que dependen de circunstancias sociopolíticas específicas, que proveen la legitimidad requerida a estas operaciones destinadas a transformar la realidad social.

En esta parte del artículo (3.1.) primero exploro los mecanismos de exclusión jurídica, centrándome en la aplicación arbitraria de la ley por parte de los funcionarios de la primera línea, en sus interacciones con los inmigrantes indocumentados ${ }^{17}$. Sobre esa base, sigo a Barsky en cuanto a prestar especial atención al papel del lenguaje (3.2.) y, en particular, de los discursos sociales sobre los inmigrantes indocumentados, como un mecanismo de exclusión sociopolítica en las sociedades occidentales contemporáneas ${ }^{18}$.

natural o más razonable del mundo". (Dayan, C., The Law is a White Dog. How Legal Rituals Make and Unmake Persons, New Jersey, Princeton University Press, 2011, pp. 150-151).

${ }^{17}$ La razón para concentrarme en este contexto específico es que estos encuentros, como hemos visto, tienen particularmente el poder de predeterminar todas las futuras interacciones jurídicas de los inmigrantes. Esto, sin embargo, no significa que la impredecibilidad y la arbitrariedad cesen en las primeras líneas. Es cierto, como observa Barsky, que una vez que un individuo "entra al sistema", por ejemplo, al ser arrestado, las "restricciones y la lógica del proceso entero cambian" ya que "el sistema [se convierte] en uno más codificado" (Barsky, R., op. cit., p. 9). Aquí, "las reglas, regulaciones y leyes son aplicadas con mayor sistematización, y como consecuencia, el rango de posibles resultados es usualmente reducido" (Ibidem, p. 99). El punto central de la monografía de Barsky son los mecanismos que producen precariedad jurídica y que son utilizados en las diferentes etapas de interacción entre los inmigrantes indocumentados y el sistema jurídico del país anfitrión. Barsky los analiza en orden cronológico: primero los encuentros en la primera línea con los funcionarios del país anfitrión (Capítulo 3); luego la fase subsiguiente de arresto y juicio en los tribunales (Capítulo 4); después el período de encarcelamiento (Capítulo 5) y por último la eventual deportación (Capítulo 6).

${ }^{18}$ Así como la ilegalidad de los inmigrantes está condicionada por consideraciones jurídico-políticas concretas en un lugar y tiempo determinados, también los mecanismos específicos de su exclusión son resultado de circunstancias contingentes (históricas, geográficas, políticas, económicas, jurídicas, etc.). Aquí solo me ocupo de un conjunto específico de mecanismos jurídicos y sociopolíticos de exclusión, empleados en el contexto de las migraciones masivas contemporáneas, predominantemente de personas de África y Asia a países europeos y otros países occidentales, como los Estados Unidos y Australia. 
Matija Žgur

\subsection{Personas "ilegales" y la arbitrariedad de los funciona- rios de la primera línea}

El punto central que Barsky plantea en su libro es que la arbitrariedad es la característica principal del modo en que aplican el derecho los funcionarios en casos que involucran inmigrantes indocumentados, particularmente en las interacciones que se producen en la primera línea. Esta arbitrariedad - continúa el argumento- es posible en buena medida gracias al carácter ilegal de los inmigrantes indocumentados, lo que trae como resultado "hacer todavía más vulnerable a una población de personas predominantemente pobres y marginalizadas, así como exponerla a niveles extremos de abuso" ${ }^{19}$.

Los efectos de tal arbitrariedad al aplicar la ley pueden verse, por ejemplo, en la alta probabilidad estadística de que un inmigrante sea detenido por un funcionario a causa de su color de piel $^{20}$; o de que sea acosado por algún funcionario debido a la incapacidad de hablar el idioma local; o de algún otro trato discriminatorio similar ${ }^{21}$. Sin embargo, más que tal ejercicio totalmente arbitrario del poder oficial, lo que enfáticamente caracteriza la precaria posición jurídica de los inmigrantes en sus interacciones con funcionarios de la primera línea es la completa impredecibilidad de cómo se llevarán a cabo tales interacciones y de cuáles consecuencias tendrán para los inmigrantes. Así, lo que se ve aquí como el problema central no es tanto la arbitrariedad en el uso del poder oficial per se (aunque sí es una gran parte del problema), sino el gran espacio que hay para la arbitrariedad

19 Barsky, R., op. cit., p. x.

20 Véase, por ejemplo: Vito, A., Grossi, E., Higgins, G., “The Issue of Racial Profiling in Traffic Stop Citations", Journal of Contemporary Criminal Justice, 33, 3, 2017, pp. 431-450; Baumgartner, F., Epp, D., Shoub, K., op. cit. Varios estudios también muestran que el número de extranjeros encarcelados ha aumentado en los últimos años en todos los países occidentales. Ugelvik, T., “The incarceration of foreigners in European prisons”, en Pickering, S. and Ham, J. (eds), The Routledge Handbook on Crime and International Migration. London \& New York, Routledge, 2014, pp. 107-120; Plesničar, M.M. and Kukavica, J., "Punishing the Alien: The Sentencing of Foreign Offenders in Slovenia", Dve domovini - Two homelands, 49, 2019, pp. 27-50.

21 Véase De Schutter, O., Links between migration and discrimination (report for the European Commission), Luxembourg, Publications Office of the European Union, 2009. 
¿Por quién doblan las campanas del Derecho? Sobre la exclusión jurídica...

entendida en un sentido amplio que incluye la posibilidad de elegir si el derecho será aplicado o no y, en caso de ser aplicado, cuáles normas deben aplicarse y, finalmente, de qué manera deben aplicarse.

Comenzaré por examinar el concepto de arbitrariedad y cómo lo entiende Barsky (llamémosle arbitrariedad en sentido estricto). Luego, indagaré cómo la arbitrariedad se manifiesta en circunstancias particulares (arbitrariedad en sentido amplio).

Barsky invoca primero la concepción de arbitrariedad que ofrece Endi$\operatorname{cott}^{22}$. Endicott distingue gobierno arbitrario - una forma de gobierno contrario al Estado de derecho (Rule of Law), que sustituye a este último por "la mera voluntad de los gobernantes"23 - de una decisión arbitraria- que se define como "un acto injustificado, un capricho o un acto despótico que demanda (y carece) de otra justificación que no sea el hecho que el agente así lo deseó y así lo llevó a cabo (y potencialmente exige el control de otra autoridad que no sea el mismo agente)"24. Una decisión arbitraria es, por lo tanto, esencialmente una decisión injustificada; a su vez, una decisión es injustificada cuando no es razonable. En lo que respecta a esto último, la Corte Suprema estadounidense ha fijado un estándar de razonabilidad para las decisiones gubernamentales en el caso Motor Vehicle Manufacturers Association v. State Farm Auto Mutual Insurance Co ${ }^{25}$. Allí, la Corte sostuvo que una decisión arbitraria por parte de una agencia del ejecutivo es aquella que "se ha basado en factores que el Congreso no ha tenido la intención de considerar; que no consideró en absoluto un aspecto importante del problema; que ofreció una explicación de su decisión que es contraria a la

22 Véase Barsky, R., op. cit., pp. 16-17.

${ }^{23}$ Endicott, T., "Arbitrariness", Canadian Journal of Law and Jurisprudence, XXXVII, 1, 2014, pág. 49. Aquí, me refiero únicamente al ideal formal de Estado de Derecho. Sobre los requisitos del ideal formal de Estado de Derecho, véase Fuller, L., The Morality of Law. Revised ed., New Haven-London, Yale University Press, 1969, cap. 2; Sobre las diferencias entre las teorías formales y las teorías sustantivas de Estado de derecho, véase Craig, pág., "Formal and Substantive Conceptions of the Rule of Law: An Analytical Framework", Public Law, 1997, pp. 467-487.

${ }^{24}$ Endicott, T., "The Reasons of the Law", The American Journal of Jurisprudence, 48, 2003, p. 90.

25463 U.S. 29 (1983). 
Matija Žgur

evidencia ante la agencia o que es tan inverosímil que no podría atribuirse a una diferencia de perspectiva o al resultado de la pericia de la agencia"26.

Aunque esta concepción parece perfectamente adecuada para evaluar las acciones de los funcionarios de la primera línea, Barsky la encuentra insuficiente. En cambio, retoma la idea de R. George Wright según la cual la arbitrariedad es un fenómeno relativo y dependiente del contexto. Wright sostiene que el significado de arbitrariedad es, de hecho, "una variedad de significados dependientes de varios contextos, que reflejan diferencias en propósitos e intereses y la consecuente gravedad -los riesgos- según los diversos actores involucrados directa o indirectamente" 27 . La perspectiva de Barsky adopta dos argumentos que son relevantes para la discusión. Primero, asume que la arbitrariedad no es cualitativamente diferente de discreción, ya que la arbitrariedad en el derecho existe "sobre una especie de continuum que empieza con la discreción, se extiende hacia la arbitrariedad y en algunos casos puede terminar convirtiéndose en ficción"28. Segundo, desde esta perspectiva, que una decisión pueda o no considerarse arbitraria depende principalmente de la gravedad de la situación. Así, por ejemplo, "denegar la licencia de pesca recreativa a un vacacionista y la imposición de la pena de muerte podrían, en casos particulares, ser arbitrarias, pero podemos ver que la gravedad o la seriedad de los intereses en juego en los dos casos pueden variar sustancialmente"29.

Sobre la base de estas consideraciones, Barsky sostiene que "puede haber arbitrariedad positiva y negativa, dependiendo de las propias pers-

${ }^{26}$ Por otro lado, un acto es razonable si, sencillamente, es "guiado por razones que deberían guiar [las propias] acciones". Véase Endicott, T., Administrative Law ( $2^{\text {nd }}$ ed.), Oxford, Oxford University Press, 2011, p. 46. Un estándar sustancialmente similar se encuentra en el caso británico Wednesbury (Associated Provincial Picture Houses Ltd v Wednesbury Corporation [1948] 1 KB 223 (CA)). De acuerdo con este estándar, que también se aplica en otras jurisdicciones, el ejercicio de un poder discrecional es irrazonable cuando: (i) "ninguna persona sensata podría incluso soñar que estaba dentro de los poderes de la autoridad"; (ii) "puede describirse como una acción realizada de mala fe"; y (iii) "ninguna autoridad razonable podría haber llegado a ello". Ibidem, p. 45.

27 Wright, G., "Arbitrariness: Why the Most Important Idea in Administrative Law Can't Be Defined, and What This means for the Law in General", University of Richmond Law Review, 44, 2, 2010, pp. 851-852.

28 Barsky, R., op. cit., p. 16.

${ }^{29}$ Wright, G., op. cit., p. 846. 
¿Por quién doblan las campanas del Derecho? Sobre la exclusión jurídica...

pectivas y posturas políticas, así como puede haber discrecionalidad positiva y negativa" ${ }^{30}$. Así, dependiendo del contexto, "la arbitrariedad y la discrecionalidad pueden ser extremadamente valiosas"31 — ya que permiten la negociación en las interacciones que se dan entre funcionarios e inmigrantes indocumentados- o, "pueden ser dañinas si los funcionarios empoderados del país anfitrión ejercen su derecho, o su responsabilidad, para actuar como funcionarios draconianos en todas las interacciones posibles con inmigrantes" 32 . Finalmente, argumenta Barsky, "ni la arbitrariedad, ni la discrecionalidad son en sí mismas problemáticas desde esta perspectiva, lo que importa es cómo son usadas"33.

El razonamiento de Barsky parece claro: ninguna institución de gobierno o regulación jurídica es malévola en sí misma; al final, son los funcionarios encargados de implementar la ley — los oficiales de policía, los agentes de aduanas, etc.—, quienes tienen la responsabilidad de cómo será ejercido el poder institucional. Por consiguiente, la amplia discrecionalidad de facto y la más limitada discrecionalidad de iure con las que cuentan los funcionarios, especialmente en el ámbito de la inmigración, pueden ser usadas en igual medida para hacer el bien o para hacer el mal.

Si lo que sostiene Barsky se entiende de manera normativa, como una apelación a que los funcionarios deben usar sus poderes con autocontrol e implementar la ley de manera empática con la situación de los inmigrantes, entonces no encuentro ningún problema con ello. No obstante, como descripción de aquello en lo que consiste (o al menos de lo que es comúnmente entendido por) la arbitrariedad en el derecho, creo que su posición es insostenible por al menos dos razones. La primera es que al ubicar la discrecionalidad y la arbitrariedad en el mismo plano cualitativo y argumentar que la discrecionalidad es meramente una subcategoría de la $\operatorname{arbitrariedad}^{34}$, traiciona la sustancia de ambos conceptos y se desvía del significado arraigado que ambos tienen en el campo jurídico. En cambio, junto con Endicott, propongo que la discrecionalidad sea entendida como

\footnotetext{
30 Barsky, R., op. cit., p. 19.

31 Ibidem, p. 21.

32 Idem.

33 Idem. Énfasis propio.

34 Véase Barsky, R., op. cit., p.19.
} 
Matija Žgur

"libertad de elección (entre opciones que pueden ser limitadas) que debe ser ejercida de manera responsable" 35 . Esto significa que "la elección no se hará para el beneficio personal de quien toma la elección, sino a favor de los propósitos que las personas encargadas de tomar esas elecciones son responsables de perseguir, en nombre de la comunidad"36. En resumen: la diferencia principal entre arbitrariedad y discrecionalidad es que una decisión discrecional es de todos modos responsable. A su vez, una decisión responsable es razonable, y como ya sabemos, una decisión razonable es exactamente lo opuesto a una decisión irrazonable, caprichosa o despótica.

En segundo lugar, independientemente de sus resultados en casos particulares, la decisión arbitraria nunca debe percibirse como una forma deseable (valiosa) de implementar el derecho, ya que representa una violación del ideal de Estado de derecho, en particular de la exigencia de congruencia. Esta última puede entenderse ya sea como un valor instrumental para el sistema jurídico o como una característica moralmente deseable del mismo $^{37}$. En la primera lectura (el Estado de derecho como instrumento), la congruencia exige que para que un orden jurídico sea funcional, es decir, eficaz para guiar el comportamiento de sus destinatarios, tiene que haber un grado considerable de coincidencia entre la ley adoptada (el derecho en los libros) y la ley tal como es realmente implementada por los funcionarios (el derecho en acción $)^{38}$. El problema con la incongruencia es que si las normas resultantes de las decisiones tomadas por los funcionarios no son en buena medida las normas contenidas en los libros ${ }^{39}$, entonces "el derecho

${ }^{35}$ Endicott, T., Administrative Law, op. cit., p. 239.

36 Ibidem, p. 234.

37 Esto es un reflejo del hecho de que el propio Estado de derecho puede entenderse como una condición necesaria para la existencia de un orden legal eficiente o como un ideal moral. Sobre esta distinción, véase Kramer, M., Objectivity and the Rule of Law, Cambridge, Cambridge University Press, 2007, cap. 2.

${ }^{38} \mathrm{Si}$ bien me enfoco solo en las acciones de los funcionarios que aplican la ley, no estoy olvidando el hecho de que si los documentos normativos sobre inmigración violan otras condiciones del Estado de derecho, aumentan la probabilidad de que se apliquen arbitrariamente. Sobre el requisito de congruencia, véase Fuller, L., op. cit., pp. 81 y ss. Véase Kramer, M., op. cit., p. 134 y ss., Marmor, A., "The Rule of Law and Its Limits", Law and Philosophy, 23,2004, p. 34 y ss.

39 En este caso, no considero la distinción entre disposiciones normativas y normas: las primeras son declaraciones contenidas en fuentes legales formales (por ejemplo, estatutos) y 
¿Por quién doblan las campanas del Derecho? Sobre la exclusión jurídica...

en la práctica” carece de referencia en el derecho promulgado. En consecuencia, "su estatus como derecho en la práctica se deshace", lo que significa que "no puede desempeñar adecuadamente el papel de guía y coordinación característico de cualquier orden jurídico real" 40 . Si bien cierta cantidad de incongruencia puede ser aceptable e incluso deseable, una vez que la discrepancia es demasiado grande, entonces, dice Kramer, podemos encontrarnos en una situación en la que "un sistema de gobierno extrañamente bifurcado ha suplantado al sistema jurídico genuino que existía"41. Por lo tanto, si, como afirma Barsky, las leyes de inmigración en EEUU (o en cualquier otro lugar) se aplican de manera desigual e inconsistente, a pesar del hecho de que algunas de estas decisiones arbitrarias pueden ser beneficiosas para los inmigrantes, tal estado de cosas indiscutiblemente viola la exigencia de congruencia del ideal de Estado de derecho y justifica la pregunta de Barsky acerca de en qué "consiste un sistema jurídico que se aplica a personas consideradas ilegales, indocumentadas o sans papiers" ${ }^{\prime 2}$.

La coincidencia apropiada entre el derecho en los libros y derecho en acción se puede lograr de varias maneras. Kramer, por ejemplo, enfatiza la objetividad de los funcionarios entendida como imparcialidad ${ }^{43}$. Según Kramer, la imparcialidad debe entenderse como "desinterés y apertura mental” y representa lo contrario al prejuicio, el partidismo, la impetuosi-

las últimas el contenido en el sentido de estas declaraciones. Si bien esta distinción se refiere precisamente a la cuestión de la interpretación por parte de los funcionarios, presupongo que la cuestión de la arbitrariedad queda claramente fuera del marco de cualquier interpretación sensata de una disposición normativa determinada. Véase Guastini, R., Interpretare e argomentare, Milano, Giuffrè, 2011, parte I, cap. IV.

${ }^{40}$ Kramer, M., op. cit., p. 137.

${ }^{41}$ Ibidem, p. 136. Los extremos a los que puede conducirse esta bifurcación se analizan maravillosamente en el notable trabajo de Ernst Fraenkel sobre los primeros años del sistema jurídico nazi. Véase Fraenkel, E., The Dual State, Clark (N.J.), The Lawbook Exchange, 2010 (1941).

${ }^{42}$ Barsky, R., op. cit., p. 107. Este problema se discute de nuevo más adelante.

${ }^{43}$ Kramer agrega a esto la condición de "dominio en la interpretación legal". Véase Kramer, M., op. cit., pp. 135 y 139 y ss.. Kramer distingue entre diferentes concepciones de objetividad, que concibe en tres grandes grupos, a saber: (i) las orientadas ontológicamente, (ii) las orientadas epistemológicamente y (iii) las concepciones de objetividad orientadas semánticamente. La objetividad entendida como imparcialidad encaja en el grupo de concepciones epistemológicas, que están principalmente interesadas en cómo los agentes racionales forman sus opiniones sobre ciertos asuntos. Véase Ibidem, p. 2 y ss. 
Matija Žgur

dad y el capricho ${ }^{44}$. Si bien el desinterés significa "la ausencia de cualquier predilección en las propias decisiones" 45 , tener una mente abierta significa "la ausencia de prejuicios y favoritismo", así como también "la ausencia de caprichos e impetuosidad"46. La contribución clave que la imparcialidad aporta a los procesos de toma de decisiones de los funcionarios reside en su confiabilidad epistémica. Bajo el ideal del Estado de derecho, los funcionarios están obligados a adoptar sus decisiones exclusivamente sobre la base de condiciones predeterminadas por las normas legales aplicables (el derecho en los libros) $)^{47}$. La "imparcialidad", argumenta Kramer, "aumenta notablemente la probabilidad de que estos resultados sean correctos", es decir, basados solo en los criterios prescritos ${ }^{48}$.

${ }^{44}$ Ibidem, p. 53. La imparcialidad, por supuesto, no es la única condición para garantizar la superposición adecuada entre el derecho en los libros y el derecho en acción, pero es una condición necesaria para ello.

${ }^{45}$ Según Kramer, también puede significar "la capacidad de dejar que la decisión no se vea afectada por la conciencia de que uno tiene un interés en ello" (Ibidem, p. 54). Sin embargo, Kramer enfatiza que la imparcialidad en este caso no es tan fuerte como cuando "no hay un interés personal por parte de cualquiera que emita un juicio sobre el asunto". (Ibidem, p. 55).

${ }^{46}$ Ibidem, p. 54. Endicott, entre otros, ofrece una definición muy similar de imparcialidad. Véase Endicott, Administrative Law, op. cit., p. 154. La imparcialidad en este sentido debe entenderse como un estado mental (apropiado). Tanto Endicott como Kramer entienden la imparcialidad, más o menos explícitamente, de las siguientes tres formas: (i) como un estado mental, es decir, como ausencia de ciertas consideraciones injustificadas, discriminatorias, (in)conscientes con respecto al procedimiento, las partes allí presentes, o el propio papel (como juez) en relación con ambos; (ii) como condición institucional, es decir, como requisito para la existencia de un conjunto de restricciones con respecto a las acciones del adjudicador (lo que debería reducir los efectos del sesgo); y (iii) como un valor moral (más sobre el punto (ii) y (iii) a continuación). Véase Papayannis, D., "Independence, impartiality and neutrality in legal adjudication", Revus - Journal for Constitutional Theory and Philosophy of Law, 28, 2016, p. 34 y ss.

47 Rothstein y Teorell enfatizan este aspecto de la imparcialidad. Véase Rothstein, B., Teorell, J., "What Is Quality of Government? A Theory of Impartial Government Institutions", Governance: An International Journal of Policy, Administration, and Institutions, 21, 2, 2008, p. 170.

${ }^{48}$ Kramer, op. cit., p. 65. Un factor clave para lograr la imparcialidad en este sentido es el establecimiento dentro del sistema jurídico (y para uso de los funcionarios) de un sistema de instrumentos "a través de los cuales ellos [los funcionarios] pueden conocer todos los hechos razonablemente verificables que se relacionan con las cuestiones legales a las que tienen que dar respuesta". Kramer enfatiza que este requisito puede satisfacerse con más de 
¿Por quién doblan las campanas del Derecho? Sobre la exclusión jurídica...

Por otro lado, los factores que alejan a los funcionarios de la imparcialidad incluyen el interés propio, el prejuicio, la ignorancia, etc. ${ }^{49}$. Sin entrar en detalles, parece bastante plausible concluir que el estado de ánimo diario del funcionario (su acuerdo con las opiniones xenófobas de Donald Trump o la simple aceptación inconsciente del "conocimiento común" ${ }^{0}$ que presenta a los mexicanos como parásitos) encaja en la categoría de factores que, podemos razonablemente suponer, el legislador no consideró como aquellos en los que deberían basarse las decisiones concretas. Por lo tanto, la toma de decisiones basadas en estos factores ha de ser considerada, como ya se ha dicho, irrazonable e ilegítima ${ }^{51}$.

Finalmente, la aplicación imparcial de la ley también tiene un valor moral específico: instrumentalmente tiene un valor moral porque mejora la capacidad de los funcionarios para comprender y aplicar las leyes correctamente, es decir, los ayuda a alcanzar los objetivos moralmente valiosos que persiguen dichas leyes ${ }^{52}$. En el mismo sentido, la imparcialidad es una cualidad valiosa porque "ayuda a las personas a cumplir sus expectativas de manera legítima", es decir, "promueve el objetivo moralmente digno de defender las creen-

un conjunto de técnicas de recopilación de información. Sin embargo, en cualquier caso, tales técnicas casi siempre deberán incluir la participación de todos los involucrados en el conflcito en el proceso de recopilación de información, así como de los testigos y otras personas que poseen información relevante. Véase Ibidem, p. 60 y ss.

49 Ibidem, p. 134 y ss.

${ }^{50}$ De tal conocimiento común, Dal Lago sostiene que, aunque empíricamente carece de fundamento, la sociedad le atribuye el estatus de las verdades tautológicas debido al solo hecho de que todos piensan que ello (es decir, el contenido del conocimiento común) es el caso. Véase Dal Lago, A., Non-persone. L'esclusione dei migranti in una società globale, Feltrinelli, Milano, 1999 ( $5^{\text {ta }}$ ed. 2012), p. 50 y ss.

${ }^{51}$ Esto, sin embargo, no significa que alguien guiado en sus acciones por factores que afectan la imparcialidad nunca pueda llegar a una decisión correcta. Esto puede ciertamente ocurrir. Sin embargo, como señala Kramer, "ese resultado feliz se produciría a pesar de la ausencia de imparcialidad y no por esa ausencia” (Ibidem, p. 134).

${ }^{52}$ La presuposición aquí es que estamos en un régimen jurídico razonablemente justo, liberal-democrático. Sin embargo, no hay una conexión necesaria entre el respeto de las condiciones del Estado de Derecho y la justicia del sistema jurídico. Raz, por ejemplo, sostiene que la conformidad con las exigencias del Estado de Derecho es totalmente compatible incluso con las violaciones más atroces de los derechos humanos. (Véase Raz, "The Rule of Law and its Virtue", en Authority of Law. Essays on Law and Morality, Oxford, Oxford University Press, pp. 211, 220 y ss.). 
cias razonables de los ciudadanos con respecto a las consecuencias jurídicas de sus acciones" ${ }^{\prime 3}$. En última instancia, la imparcialidad también tiene un valor moral ya que "no solo ayuda a asegurar que los funcionarios tomen decisiones moralmente correctas, sino que además los ayuda a tomar tales decisiones motivados por las razones moralmente correctas" ${ }^{24}$.

Al pasar ahora al segundo tema (cómo se manifiesta la aplicación arbitraria de la ley en los casos relacionados con inmigrantes indocumentados) debemos advertir ante todo que no estamos tratando con un problema homogéneo, sino con tres problemas distintos, a saber: (i) en primer lugar, si el derecho (cualquiera que sea) se aplicará; (ii) qué norma se aplicará en un caso particular; y (iii) cómo se aplicará esa norma. Examinemos cada uno brevemente.

El primer caso (i) depende principalmente de la opinión pública y de consideraciones políticas más amplias con respecto a la inmigración y, en menor medida, de consideraciones morales individuales de los funcionarios encargados de aplicar la ley. Un ejemplo de la no aplicación de leyes de inmigración motivada políticamente es el caso de los Dreamers: personas indocumentadas que llegaron ilegalmente a Estados Unidos ${ }^{55}$ siendo niños y han sido a lo largo de sus vidas, a causa de su estatus de residente "ilegal", susceptibles de deportación. Sin embargo, dadas las condiciones bajo las cuales fueron traídas al país, en conjunción con el hecho de que desde entonces han vivido en Estados Unidos llevando en la mayoría de los casos vidas ejemplares, la decisión de deportarlas ha sido altamente impopular. Por lo tanto, como una cuestión de política oficial (implementada a través de órdenes ejecutivas), las administraciones anteriores impidieron su

53 Kramer, M., op. cit., p. 175.

54 Ibidem, pp. 175-176.

55 El término DREAMER se deriva del proyecto de ley Development, Relief, and Education for Alien Minors Act, en breve DREAM, que permitiría a estas personas obtener la residencia permanente en los Estados Unidos. El proyecto de ley se propuso por primera vez en 2001 y desde entonces se ha vuelto a introducir varias veces, pero nunca obtuvo el apoyo suficiente en el Congreso de los Estados Unidos. Para más información sobre el caso y la historia legislativa, véase $<$ https://www.americanimmigrationcouncil.org/research/dreamact-daca-and-other-policies-designed-protect-dreamers $>\mathrm{y}<\mathrm{https} / /$ www.law.uh.edu/ihelg/ documents/Statute-TableThree.html>. 
¿Por quién doblan las campanas del Derecho? Sobre la exclusión jurídica...

deportación ${ }^{56}$. El actual presidente de los Estados Unidos, Donald Trump, se opuso a esta política de no deportación y, desde que asumió el cargo, ha trabajado para desmantelarla. Viendo el estado actual de la cuestión, es imposible estimar si este cambio de política tendrá lugar o no y, de ser el caso, cuándo entrará en vigor. Entre tanto, se coloca a los Dreamers en una posición extremadamente precaria, ya que no pueden determinar razonablemente si serán deportados o no en un futuro cercano y, por lo tanto, son incapaces de organizar sus acciones y actividades futuras ${ }^{57}$.

En este sentido, Kramer reconoce que, a veces, "la evaluación imparcial de una situación es contraria a la conclusión de que las leyes aplicables deben ser efectivamente aplicadas" 58 . Si bien la mayoría de las normas de en un ordenamiento jurídico liberal, democrático y eficiente deben aplicarse, pueden surgir circunstancias en las cuales un funcionario estará moralmente obligado a abstenerse de aplicar ciertas normas, por ejemplo, si ello viola el principio básico de igualdad, las expectativas legítimas de los interesados o debido a alguna otra razón de peso ${ }^{59}$. Si bien esta conclusión puede aceptarse, no cambia el hecho de que "la no-aplicación, en todos los niveles, es la raíz de la confusión que tienen los inmigrantes indocumentados con respecto a si (o cómo) las diversas leyes relacionadas con las personas indocumentadas serán aplicadas en sus casos particulares" 60 . Por lo tanto, la no aplicación de leyes de inmigración válidas, independientemente de si funciona a favor o en contra de los intereses de los inmigrantes, representa un elemento importante de la arbitrariedad en sentido amplio

${ }^{56}$ Los cambios legislativos que evitarían su deportación y les permitirían obtener la residencia permanente se propusieron bajo la administración del presidente Bush y del presidente Obama. Si bien apoyaron la mayoría de estas propuestas, nunca obtuvieron una mayoría suficiente en el Congreso.

${ }^{57}$ Con respecto a la agónica impredecibilidad debida a encontrarse constantemente los inmigrantes indocumentados en condición de deportación, el análisis de D.M. Carter sobre la "revocabilidad de la promesa del futuro" es particularmente revelador. Véase Carter, D.M., State of Grace. Senegalese in Italy and the New European Immigration, London-Minneapolis, University of Minnesota Press, 1997, p. 196.

${ }^{58}$ Kramer, M., op. cit., p. 180.

${ }^{59}$ Idem.

${ }^{60}$ Barsky, R., op. cit., p. 22. 
Matija Žgur

que experimentan los inmigrantes y contribuye a la precariedad de su posición jurídica.

En cuanto al segundo (ii) problema (cuál norma será aplicada), es conveniente señalar que pueden surgir complicaciones cuando en un caso determinado se pueden aplicar normas provenientes de dos o más actos normativos diferentes, y que producen resultados conflictivos (el problema de las antinomias ${ }^{61}$. En un estado federal, como Estados Unidos, las normas estatales pueden a veces entrar en conflicto con la ley federal. Un ejemplo de ello es la tensión entre las leyes federales de inmigración de Estados Unidos y las normas de inmigración promulgadas por el Estado de Arizona en 2010. El Proyecto de Ley 1070 del Senado del Estado de Arizona fue una de las leyes de inmigración más estrictas de Estados Unidos. Exigía, entre otras cosas, que los funcionarios encargados de aplicar la ley comprobaran necesariamente el estatus migratorio de cualquier persona de la que razonablemente sospecharan que se encontraba ilegalmente en Estados Unidos ${ }^{62}$. La principal objeción planteada contra esta exigencia fue que reforzaba los prejuicios raciales ${ }^{63}$. Debido a su naturaleza controvertida, la ley sufrió numerosos cuestionamientos ante los tribunales federales, que finalmente tuvieron éxito. Como resultado, la ley se modificó varias veces, y esto hizo que conocer el contenido exacto de la ley válida en un momento determinado fuera extremadamente difícil, aumentando aún más la imprevisibilidad jurídica para las personas afectadas ${ }^{64}$.

Finalmente, en referencia al tercer (iii) problema, es decir, a cómo se aplicará la ley, vimos en nuestro ejemplo inicial el grado de libertad que tiene un oficial de tránsito para decidir qué acción tomar contra un individuo del cual sospecha que es un extranjero indocumentado. En cualquier variación sobre tal encuentro, algunas de las acciones que están disponi-

${ }^{61}$ Sobre antinomias en general, véase Guastini, R., op. cit., parte II, cap. 1.

${ }^{62}$ En una orden ejecutiva separada, el Gobernador del Estado de Arizona exigió que se establecieran criterios de orientación claros sobre lo que constituye sospecha razonable.

${ }^{63}$ Para más sobre el asunto, véase: https://www.aclu.org/other/frequently-asked-questions-about-arizona-racial-profiling-law. En general sobre perfiles raciales, véase supra, nota 1 .

${ }^{64}$ En términos del ideal del Estado de derecho, podríamos decir que esto representó una violación del requisito de constancia. Véase, por ejemplo, Fuller, L., op. cit., pp. 79-81. 
¿Por quién doblan las campanas del Derecho? Sobre la exclusión jurídica...

bles de facto para él ya estarán delimitadas por la ley ${ }^{65}$. Otras acciones, sin embargo, no están igualmente limitadas. Por ejemplo, que el oficial consulte o no con las agencias federales sobre el estado migratorio de la persona detenida depende completamente de su propia elección. Lo que nos preocupa aquí no es el alcance de la discreción que la ley otorga al oficial. Más bien, lo que importa aquí es que las decisiones del oficial en tales casos pueden estar completamente desvinculadas de los criterios jurídicos predeterminados o de las políticas de aplicación de la ley y ser, en cambio, el producto de factores conocidos únicamente por el oficial y desconocidos para el resto. Esos factores incluyen, entre los más problemáticos, el racismo, la xenofobia y otros estereotipos y prejuicios contra los inmigrantes indocumentados ${ }^{66}$. Como ya hemos establecido, si alguno de estos factores subyace efectivamente a las decisiones del funcionario, su decisión debe considerarse arbitraria y, por lo tanto, violatoria del ideal del Estado de derecho.

$\mathrm{Al}$ analizar el concepto de arbitrariedad y sus manifestaciones en las interacciones en la primera línea entre los inmigrantes indocumentados y los funcionarios del país anfitrión, establecimos que el núcleo de la arbitrariedad está representado por la toma de decisiones basada en factores irrazonables, como el estado de ánimo de los oficiales, sus opiniones políticas personales o similares. Las decisiones basadas en tales factores son epistemológicamente poco confiables y, por lo tanto, conducen a discrepancias entre el derecho en los libros y el derecho en acción. De esta manera, esas decisiones impiden a los destinatarios de las directivas jurídicas (en este caso, los inmigrantes indocumentados) pronosticar razonablemente las consecuencias de sus acciones futuras. En consecuencia, su precariedad jurídica y su vulnerabilidad social no hacen más que profundizarse. También vimos que las decisiones arbitrarias se ven influidas por la opi-

${ }^{65}$ Inspeccionar un vehículo detenido en la vía pública, por ejemplo, exige que la policía demuestre una causa probable: "una cantidad razonable de sospecha, respaldada por circunstancias lo suficientemente fuertes como para justificar la creencia que puede tener una persona prudente de que ciertos hechos probablemente son ciertos". Debido al lenguaje altamente vago usado en tales estándares, incluso tales acciones son extremadamente difíciles de revisar ex post, e incluso tales revisiones a menudo son criticadas por ser arbitrarias.

${ }^{66}$ Véase Barsky, R., op. cit., p. 18. 
Matija Žgur

nión que el público en general, los políticos en el poder y los funcionarios individuales tienen sobre los inmigrantes indocumentados. Por ello, me alejo ahora del derecho para concentrarme en el entorno social que rodea a los inmigrantes indocumentados en los países de acogida. Examino las características de los debates públicos que tienen lugar en los países anfitriones con respecto a los inmigrantes indocumentados y trato de establecer cómo estas narrativas excluyentes contribuyen a la exclusión jurídica de esos inmigrantes.

\section{2. "Otras" personas y discursos sociales excluyentes respecto a los inmigrantes indocumentados}

Cuando Ann Coulter, una influyente comentarista conservadora, acusa a los inmigrantes "ilegales" que ingresan a Estados Unidos de ser criminales peligrosos, parásitos que explotan el sistema de bienestar social y de quitarles el empleo a los ciudadanos legítimos, está construyendo una imagen obviamente paradójica y altamente generalizada de quiénes son estas personas y qué efecto tienen en su sociedad de acogida ${ }^{67}$. Sin embargo, su narrativa no es accidental y tiene un propósito claro: si bien carece de fundamento empírico, sus palabras están emotivamente cargadas y, por lo tanto, tienen la intención de llegar al núcleo de los temores y preconcepciones de aquellos estadounidenses que ya de por sí batallan contra el desempleo y los efectos de una sistema de seguridad social cada vez más empobrecido. Al abogar por una firme posición antiinmigrante, Coulter busca persuadir a millones de estadounidenses de los peligros que representan los inmigrantes indocumentados y, al hacerlo, busca directamente producir cambios en las políticas públicas y la legislación ${ }^{68}$.

El término inmigrantes de Schrödinger se ha introducido en la cultura popular para denominar este tipo de representaciones paradójicas de los inmigrantes. Para conocer la posición de Coulter sobre estos asuntos, consulte su último libro sobre el tema: Coulter, A., ¡Adiós, America! The Left's Plan to Turn Our Country into a Third World Hellhole, Washington DC, Regnery Publishing, 2015.

${ }^{68}$ Se ha argumentado que el libro de Coulter ¡Adiós, América! influyó en los comentarios del presidente Trump sobre los mexicanos durante su campaña presidencial. Véase C. Lozada, 
¿Por quién doblan las campanas del Derecho? Sobre la exclusión jurídica...

La extendida presencia de tales narrativas demuestra que la precariedad jurídica es solo parte de un problema mayor que enfrentan los inmigrantes indocumentados en sus sociedades de acogida. Igualmente arduos son los desafíos relacionados con encontrarse en un espacio social impregnado de estereotipos negativos y de temores generales contra los extranjeros. En esta sección, examino cómo esas ideas hostiles sobre los extranjeros, y en particular sobre los inmigrantes indocumentados, entran en el debate público y cómo se convierten en mecanismos de exclusión sociopolítica de estas personas. Este análisis de orientación sociológica se basa en el argumento de Barsky sobre la relación entre los mecanismos sociopolíticos y jurídicos de exclusión. Barsky hace dos afirmaciones al respecto. Primero, argumenta que el contenido de las políticas de inmigración y de la legislación están co-determinados por los debates sociales prevalecientes sobre los inmigrantes y vicevers $a^{69}$. En segundo lugar, con respecto a la aplicación de la ley en la primera línea, afirma que una retórica negativa tan generalizada y profundamente arraigada sobre los inmigrantes contribuye a "establecer el continuum de posibilidades discrecionales, y puede desempeñar algún papel en la legitimación de las decisiones particulares tomadas por los funcionarios de la primera línea"70. En otros términos, Barsky sostiene que un círculo vicioso se establece entre la naturaleza de las políticas relacionadas con la inmigración y las características de los discursos sociales relacionados con ella: mientras que la hostilidad contra los inmigrantes (establecida y mantenida por las narrativas públicas) se extiende a la esfera jurídica — al afectar tanto la legislación como la

Did Ann Coulter's new book help inspire Trump's Mexican 'rapist' comments?, en Washington Post (3 August 2015). Disponible en: goo.gl/BFMGNS. Sobre el uso político y estratégico de tales esterotipos, véase Sindic, D. et al, "Schrodinger's immigrant: The political and strategic use of (contradictory) stereotypical traits about immigrants", Journal of Experimental Social Psychology, 79, 2018, pp. 227-238.

${ }^{69}$ Argumenta que, por un lado, "los discursos sociales prevalecientes y las doxas que se arremolinan dentro de ellos, desempeñan un papel en la determinación de los tipos de leyes o medidas que se aplican"; sin embargo, por otro lado, la influencia es recíproca ya que "las decisiones de los funcionarios de la primera línea para actuar sobre la base de estas medidas en casos particulares pueden a su vez afectar los discursos sociales" (Barsky, R., op. cit., p. $65)$.

${ }^{70}$ Idem. 
Matija Žgur

aplicación de la ley-, el contenido de esta última también se refleja en la naturaleza de esas narrativas.

Nuestro análisis de las causas y las características de estas dinámicas se basa en el argumento de que los procesos de globalización, especialmente sus consecuencias, son el factor clave que impulsa las migraciones hoy en día $^{71}$. Los conflictos armados prolongados, el cambio climático intenso, la persecución política y, sobre todo, la pobreza a gran escala son algunas de las principales razones del movimiento masivo de personas de países empobrecidos del Tercer Mundo hacia Estados occidentales más ricos ${ }^{72}$. La desigualdad cada vez mayor en la distribución de la riqueza entre el Norte Global y el Sur Global, que determina en gran parte de las corrientes migratorias, es principalmente el resultado de la expansión mundial de los mercados abiertos y los profundos cambios en la estructura de la economía global ${ }^{73}$. Por un lado, como señala Papastergiadis "la mayor parte del comercio mundial se centra ahora en opciones especulativas, acciones futuras, seguros, finanzas y bienes raíces, más que en el mercado de bienes primarios"74; por otro lado, con modos de producción más eficientes y la desregularización de los mercados laborales, los fabricantes ahora pueden

${ }^{71}$ Véase Franko Aas, K., Globalization \& crime, London, SAGE, 2007; Papastergiadis, N., The Turbulence of Migration. Globalization, Deterritorialization and Hybridity, Cambridge, Polity Press, 2000, cap. 4; Bauman, Z., Wasted Lives. Modernity and its Outcasts, Cambridge, Polity Press, 2004.; Jones, R., Violent Borders. Refugees and the Right to Move, London-New York, Verso, 2017. Lo que sigue a continuación es inevitablemente un análisis muy abstracto y superficial de fenómenos globales complejos y sus desarrollos en las últimas décadas.

${ }^{72}$ En la actualidad, dos tercios de la población mundial de inmigrantes se concentran en América del Norte, Europa occidental y oriental, y países de altos ingresos de Oriente Medio y África del Norte. Véase World Bank Group, Moving for Prosperity. Global Migration and Labor Markets, Policy Research Report, Washington, DC, 2018 (particularmente el capítulo 2).

${ }^{73} \mathrm{Si}$ bien todos los fenómenos relacionados con los inmigrantes indocumentados son muy difíciles de medir, todavía se estima que la mayoría de los inmigrantes indocumentados son migrantes laborales y trabajan en sus países de acogida ilegalmente. Véase, por ejemplo: Boswell, C., Straubaar, T., "The Illegal Employment of Foreign Workers: an Overview”, Intereconomics, 39, 1, 2004, pp. 4-7 (para el context europeo.); Borjas, G., "The Labor Supply of Undocumented Immigrants", Working Paper 22102, National Bureau of Economic Research, Cambridge (MA) (para el context estadounidense); De Genova, N., op. cit., pág. 422, y la literatura de referencia que allí se encuentra.

${ }^{74}$ Papastergiadis, N., op. cit., p. 78. 
¿Por quién doblan las campanas del Derecho? Sobre la exclusión jurídica...

producir sus productos en cualquier parte del mundo a costos cada vez más bajos ${ }^{75}$. Estas transformaciones han demostrado ser particularmente rentables para las empresas transnacionales, mientras que la población en ambos extremos de las rutas de migración (económica) ha soportado la mayor parte de los costos relacionados. Sin límites fijados por fronteras nacionales ni por los intereses de nadie más que de sus accionistas, las empresas transnacionales pueden transferir rápidamente sus operaciones a dondequiera que los costos sean menores. En vista de esto, los gobiernos de los países en desarrollo compiten por su atención, relajando continuamente las regulaciones ambientales y de seguridad laboral, reduciendo los salarios mínimos y ofreciendo a estas empresas grandes subsidios y rebajas de impuestos. A pesar de los beneficios relativos de estos procesos (es decir, la modernización y el crecimiento del empleo), el costo para su gente ha sido alto: los trabajadores en los talleres de explotación laboral de las corporaciones no reciben un salario suficiente, trabajan horas extras en condiciones peligrosas e insalubres, a menudo son hostigados y maltratados físicamente ${ }^{76}$. Por otro lado, millones de personas en estos países permanecen desempleadas u ocupando puestos de trabajo de baja categoría, lo que difícilmente les permite una vida digna. Totalmente excluidos de las relaciones económicas globales, estos individuos son un efecto secundario negativo de la globalización. Este "ejército laboral de reserva" representa el núcleo de los inmigrantes globales de hoy ${ }^{77}$.

Las consecuencias negativas de estos cambios económicos también se han hecho sentir en el mundo desarrollado. A raíz de la Segunda Guerra

${ }^{75}$ Un punto importante señalado por Jones, entre otros, es que si bien la globalización ha permitido que el capital y los bienes se muevan libremente a través de las fronteras, no ha ocurrido lo mismo con el trabajo, que sigue capturado dentro de las fronteras de los Estados-nación. Véase Jones, R., op. cit., cap. 6.

76 Véase, por ejemplo: Robertson, R., Di, H., Brown, D. and Dehejia, R., "Working Conditions, Work Outcomes, and Policy in Asian Developing Countries", ADB Economics Working Paper Series (No. 497), Asian Development Bank, 2016.

77 Esta subclase global de refugiados, solicitantes de asilo y migrantes económicos es lo que Bauman llama "el desperdicio [humano] de la globalización". Cínicamente agrega que "tal vez la única industria próspera en las tierras de los recién llegados (llamados de manera tortuosa y engañosa países en vías de desarrollo) es la producción en masa de refugiados". (Bauman, Z., op. cit., p. 73). 
Matija Žgur

Mundial, el intervencionismo estatal en las relaciones de mercado marcó el comienzo de un período sin precedentes de crecimiento económico, empleo y amplios servicios de seguridad social ${ }^{78}$. La estabilidad y la prosperidad de esta edad de oro del capitalismo permitieron el surgimiento de una clase media robusta en los países del capitalismo avanzado ${ }^{79}$. Sin embargo, en la década de 1970, cuando la recesión a gran escala afectó a gran parte del mundo occidental y el comercio se internacionalizó cada vez más, las corporaciones comenzaron a subcontratar a muchos de sus empleados en los países en desarrollo. Incapaces de competir con sus contrapartes en el tercer mundo, los trabajadores de la clase media en el Oeste experimentaron un empeoramiento sustancial de las condiciones de trabajo, la reducción de salarios y despidos masivos ${ }^{80}$. Al mismo tiempo, la victoria del modelo neoliberal a nivel nacional trajo una reducción sustancial del papel del Estado en la provisión de protecciones contra los pesares de la vejez, la enfermedad, la discapacidad y el desempleo. Los servicios de seguridad social estatales, considerados los pilares de la legitimidad del Estado después de la Segunda Guerra Mundial, continúan siendo privatizados, ya que la gestión de estas cuestiones se ha convertido en un asunto privado ${ }^{81}$. Todos estos factores contribuyeron de manera importante a la creciente insatisfacción de la debilitada clase media occidental ${ }^{82}$.

78 Véase Brett, E.A., The World Economy since the War. The Politics of Uneven Development, London, MacMillan, 1985; Marglin, S.A., Schor, J.B. (eds.), The Golden Age of Capitalism. Reinterpreting the Postwar Experience, Oxford, Clarendon Press, 1990.

79 Véase Jones, R., op. cit., pp. 124 y ss.

80 "A medida que los empleos en manufactura se mudaron al extranjero (la industria manufacturera se redujo de casi el 30 por ciento de los empleos en EEUU en 1970 al 8 por ciento en 2012), muchas de las victorias que ganaron los sindicatos (salarios altos, pensiones sustanciales, beneficios de salud) se perdieron. A los trabajadores que permanecen en los Estados Unidos hoy se les paga mucho menos que a los trabajadores sindicalizados hace una generación". (Jones, R., op. cit., p. 129).

${ }^{81}$ Véase Ibidem, p. 128 ff.; cfr. Papastergiadis, N., op. cit., p. 80.

${ }^{82}$ Refiriéndose a Austrialia, Papastergiadis describe vívidamente estas consecuencias: "En los suburbios en expansión, las familias y los lazos sociales son destrozados por las nuevas presiones económicas. Las mujeres abandonan a sus esposos fracasados. Marginados, aislados, frustrados y cada vez más enojados, los hombres caen en un círculo vicioso de abusos... La inseguridad individual, la soledad, la dislocación social, el desempleo a largo plazo, parecen ser el gran inconveniente de la globalización para la clase trabajadora". (Papastergiadis, N., op. cit., p. 80). 
¿Por quién doblan las campanas del Derecho? Sobre la exclusión jurídica...

Estas son, a grandes rasgos, las principales características del entorno sociopolítico actual en el que los refugiados y otros inmigrantes (no documentados) entran. Con el ocaso de la clase media, que busca descargar las frustraciones producto del declive de su poder económico, y con el Estado buscando bases alternativas, no económicas, para renovar su legitimación, el tema de las migraciones ha emergido en los últimos años como un denominador común alrededor del cual estas tendencias se han congregado. Como observa Bauman, dada su precaria posición, los inmigrantes, particularmente los indocumentados, ofrecen "un blanco fácil para descargar las ansiedades provocadas por los temores generalizados de la redundancia social; en el proceso, se los recluta para ayudar a los gobiernos estatales en sus esfuerzos por reafirmar su dañada y debilitada autoridad" ${ }^{83}$.

¿Cómo exactamente se convierten los inmigrantes en la efigie del "espectro de fuerzas globales" 84 ? Las estrategias y mecanismos de exclusión sociopolítica varían en relación con las contingencias del contexto histórico-político. Si, por ejemplo, el nazismo hizo aceptable calificar a los judíos como subhumanos manipuladores, parasitarios y que propagan enfermedades, la sensibilidad pública de hoy hace casi imposible tal antisemitismo manifiesto. En consecuencia, el antisemitismo de hoy se presenta bajo el disfraz de discursos mucho más refinados que incluyen hablar del asunto judío en Estados Unidos o en el revisionismo del holocausto. Dentro del contexto temporal y espacial que se examina aquí, la característica general de los procesos de exclusión relacionados con los inmigrantes ha sido de naturaleza compleja y multifacética. El reciente giro nacionalista en varios países occidentales es un buen ejemplo. A pesar de la creciente aceptación popular de la retórica agresivamente antiinmigrante de los principales políticos, los valores fundamentales bien establecidos que subyacen a las democracias occidentales (liberalismo, derechos humanos universales, multiculturalismo, etc.) parecen ser, al menos por ahora, un obstáculo importante para algunas de las ideas más extremas sobre cómo tratar a los inmigrantes indocumentados en estos países. Así, se proponen estrategias de exclusión más sofisticadas. A los fines de este artículo, me

${ }^{83}$ Bauman, Z., op. cit., p. 63.

${ }^{84}$ Ibidem, p. 66. 
Matija Žgur

enfoco en un tipo de estrategia de exclusión, a las que llamo Otredades ${ }^{85}$. Discuto dos estrategias de otredad que en los últimos años se han convertido en la respuesta dominante al problema de la inmigración. Me refiero a la primera como la estrategia de seguritización y a la segunda como la estrategia de contaminación.

En esencia, la estrategia de seguritización consiste en presentar un problema como un problema de seguridad, es decir, como un problema que excede la gravedad de los problemas políticos ordinarios y, como tal, requiere una solución por medios extraordinarios ${ }^{86}$. Esta estrategia consiste fundamentalmente en un proceso retórico ${ }^{87}$, en el que quien propone la seguritización (generalmente un agente del estado ${ }^{88}$ ), busca persuadir a un público específico (usualmente el público en general de un país o algún

${ }^{85}$ Utilizo este término ampliamente, para incluir diferentes procesos de exclusión. Cohen, por ejemplo, identifica siete tipos de exclusión social. Véase Cohen, R., Migration and its Enemies. Global Capital, Migrant Labour and the Nation-State, Aldershot, Ashgate, 2006, cap. 4.

${ }^{86}$ En este sentido, se trata de una intensificación específica en el tratamiento político de los asuntos públicos. Según Buzan y otros, los temas pueden ser (i) no politizados, lo que significa que el tema no está de ninguna manera sujeto al debate público ni a la toma de decisiones gubernamentales; (ii) politizado, lo que significa que el tema se discute públicamente y requiere una respuesta de política pública; finalmente, (iii) presentado como un asunto de seguridad, "lo que significa que el problema se presenta como una amenaza existente, que requiere medidas de emergencia y que justifica acciones fuera de los límites normales del procedimiento político". (Buzan, B., Waever, O. and de Wilde, J., Security. A New Framework for Analysis, London, Lynne Rienner Publishers, 1998, pp. 23-24). Más adelante, propongo que la criminalización de un asunto específico es un paso más en este espectro.

${ }^{87}$ Una corriente prominente en el campo de los estudios de seguridad, liderada por la Escuela de Copenhague, percibe la seguridad en términos de actos de habla. Véase, por ejemplo: Waever, O., "Securitization and desecuritization", en R. Lipschutz (ed), On Security, New York, Columbia University Press, 1995.

88 Tales agentes pueden incluir a líderes políticos, agencias ejecutivas o al gobierno como tal. Su estatus privilegiado como agentes de seguritización se debe usualmente al vasto conocimiento sobre asuntos de importancia pública que, como funcionarios del gobierno, tienen en comparación con otro tipo de actores, además de su posición de poder a priori. (Cfr. Balzacq, T., "The Three Faces of Securitization: Political Agency, Audience and Context", European Journal of International Relations, 11, 2, 2005, p. 191). Sin embargo, como Buzan y otros sostienen "nada garantiza a estos agentes su capacidad para hacer que las personas acepten una postura que demande una acción necesaria en materia de seguridad..., y nadie queda excluido de intentar articular distintas alternativas de seguridad". (Buzan, B. et al., op. cit., p. 32). 
¿Por quién doblan las campanas del Derecho? Sobre la exclusión jurídica...

otro colectivo) de la naturaleza particularmente seguritaria del problema en cuestión. Una característica importante de este proceso es que los problemas de seguridad no están predeterminados, sino que dependen del contexto $^{89}$, en particular de las entidades que supuestamente están en peligro por la amenaza de seguridad percibida ${ }^{90}$. Del mismo modo, ninguna entidad o fenómeno es, a causa de alguna característica esencial, una amenaza existencial (de seguridad) a priori. Más bien, un asunto se convierte en un problema de seguridad "no necesariamente porque existe una amenaza real, sino porque el problema se presenta [con éxito] como tal amenaza"91.

En décadas recientes, la inmigración se ha convertido en un tema central en los asuntos de seguridad ${ }^{92}$. Si bien los mecanismos concretos empleados en estos procesos varían, la seguritización de la inmigración está, como sostiene Huysmans, típicamente insertada en una lucha política más amplia "sobre los criterios culturales, raciales y socioeconómicos para

89 Balzacq vincula fuertemente el éxito de la movida de seguritización con una audiencia particular en el contexto concreto. Por lo tanto, argumenta que "el resultado positivo de presentar un problema como una amenaza a la seguridad, ya sea fuerte o débil, reside en la decisión del actor de determinar los tiempos apropiados dentro de los cuales, el reconocimiento del objeto particular presentado como amenaza, es facilitado a las masas". (Balzacq, T., op. cit., p. 182).

${ }^{90}$ Estas entidades supuestamente en peligro se mencionan como objetos referentes en la teoría de la seguritización y pueden incluir diferentes entidades militares, económicas, ambientales, sociales o políticas. Sobre esto, véase Buzan, B. et al., op. cit., p.21 y ss.

${ }^{91}$ Ibidem, p. 24.

92 Esto es evidente en la extensa literatura sobre el tema, particularmente en estudios de seguridad. Véase, por ejemplo: Huysmans, J., "The European Union and the Securitization of Migration”, Journal of Common Market Studies, 38, 5, 2000; Bigo, D., "Security and Immigration: Towards a Critique of the Governmentality of Unease", Alternatives, 27, 2002, pp. 63-92; Green, P. and Grewcock, M., "The War against Illegal Immigration: State Crime and the Construction of a European Identity", Current Issues in Criminal Justice, 14, 1, 2002, pp. 87-101; Buonfino, A., "Between Unity and Plurality: The Politicization and Securitization of the Discourse on Immigration in Europe", New Political Science, 26, 1, 2004, pp. 23-49; Huysmans, J., The Politics of Insecurity. Fear, migration and asylum in the EU, Abingdon, Routledge, 2006; Huysmans, J., Dobson, A., Prokhovnik, R. (eds.), The Politics of Protection. Sites of insecurity and political agency, London-New York, Routledge, 2006; Messina, A., "Securitizing Immigration in the Age of Terror", World Politics, 66, 3, 2014, pp. 530-559, y otros. 
Matija Žgur

la distribución de derechos y deberes y sobre los instrumentos de control aceptables para integrar a las personas dentro de una comunidad"93.

$\mathrm{Al}$ analizar la inmigración como un asunto de seguridad en el contexto de la Unión Europea, Huysmans señala que este no ha sido un proceso simple, sino que la transformación de los inmigrantes en fuentes de temor social ha sido un "proceso multidimensional en el que la inmigración y el asilo están vinculados y circulan a través de una variedad de importantes debates políticos que abarcan al menos tres temas: seguridad interna, identidad cultural y bienestar" 94 . Estos tres temas, y su relación con la inmigración, han estado en el centro de la agenda política de los Estados miembros de la Unión Europea (y también de los que no son miembros de la UE) desde la década de $1980^{95}$. Una de las dinámicas claves en este respecto ha sido el establecimiento de un vínculo causal entre, por un lado, un espacio creciente de libertad e igualdad (es decir, el mercado común, la libertad de movimiento, la igualdad en el acceso a los derechos sociales, etc.) y, por otro lado, la necesidad de delimitar claramente este espacio y protegerlo de intrusos externos, aquellos que se consideran innecesarios en el proyecto económico, culturalmente indeseables o incluso peligrosos para nuestra seguridad. De esta manera, surgió la necesidad de determinar mejor los criterios para tener derecho a acceder a esta área, una necesidad que se basó en el supuesto de que "abolir los controles fronterizos internos y facilitar los flujos transnacionales de bienes, capital, servicios y personas cambiará el orden público y el Estado de derecho"96. Esta necesidad fue apoyada por una asunción ulterior, a saber, que "el control de los movimientos ilegales de bienes, servicios y personas ocurre principalmente en la frontera" ${ }^{97}$.

${ }^{93}$ En esencia, lo que Huysmans está argumentando es que presentar al fenómeno migratorio como un asunto de seguridad se ha convertido en parte de la política de pertenencia. Huysmans, J., The Politics of Insecurity, op. cit., p. 63.

${ }^{94}$ Ibidem, p. 64.

${ }^{95}$ El hecho de que la seguritización de la migración comenzara en ese período no es sorprendente, considerando que, como ya vimos, es un momento en el cual Occidente había sufrido una grave recesión económica y un aumento del desempleo. He discutido estas cuestiones brevemente más arriba. Véase, además Huysmans, J., The Politics of Insecurity, op. cit., p. 65.

96 Ibidem, p. 69 97 Ibidem, p. 70. 
¿Por quién doblan las campanas del Derecho? Sobre la exclusión jurídica...

Junto con la maniobra adicional de vincular la inmigración con el asilo, "presentando al asilo como una vía alternativa para la inmigración económica en la UE" 98 y, finalmente, relacionando al asilo con el problema del terrorismo, tenemos como consecuencia obvia el avance de la idea de que es necesario fortalecer los controles de la frontera exterior ${ }^{99}$. De esta manera, argumenta Huysmans, se había creado un continuum de seguridad, "conectando el control de fronteras, el terrorismo, el crimen internacional y la migración". "El continuum de seguridad", prosigue Huysmans, "es un modo institucionalizado para la creación de políticas que permitan transferir las connotaciones en materia de seguridad características del terrorismo, el tráfico de drogas y el lavado de dinero hacia el área de la migración" 100 .

Otra pieza clave en el proyecto de seguritización fue un desarrollo paralelo en la esfera de la distribución de bienes socioeconómicos. A raíz de varias recesiones y el aumento del desempleo que afectó a Occidente en la década de 1970, "la lucha por la distribución de bienes sociales como vivienda, atención médica, prestaciones por desempleo, empleos y otros servicios sociales [se volvió] más competitiva" ${ }^{\text {101 }}$. La intensificación de esta lucha llevó a "una afirmación cada vez más explícita del chovinismo de bienestar, o del privilegio de los ciudadanos nacionales en la distribución de bienes sociales" ${ }^{\prime 102}$. Se ha dicho que el surgimiento de este fenómeno es "un desarrollo central a través del cual la migración y el asilo se han vinculados a dominios de inseguridad vía la cuestión del bienestar” ${ }^{103}$.

${ }^{98}$ Ibidem, p. 66.

99 Ibidem, p. 69.

${ }^{100}$ Ibidem, p. 71.

${ }^{101}$ Ibidem, p. 77.

${ }^{102}$ Ídem. Huysmans también argumenta que "para los chovinistas del bienestar social, los inmigrantes y los solicitantes de asilo no son simplemente rivales, sino beneficiarios ilegítimos de derechos socioeconómicos" (Idem). El argumento puede manifestarse en una versión más radical o más moderada. Para ambos, véase Ibidem, p.78 y ss. Nótese también cómo este discurso es sustancialmente el mismo que el empleado por Ann Coulter, de quien hemos hablado anteriormente.

${ }^{103}$ Debemos tener en cuenta que el chovinismo del bienestar también ha sido "una estrategia para introducir criterios de identidad cultural en un área en la que la pertenencia se determina sobre la base de criterios de política social, como salud, edad, discapacidad y empleo" (Ibidem, p. 78). 
Matija Žgur

Como conclusión de esta sección, no debemos pasar por alto el hecho de que en los últimos años el tema de la inmigración ha sido objeto de una mayor intensificación por parte de la retórica y las respuestas políticas a la misma. Cada vez más, los problemas derivados de la continua afluencia de un gran número de inmigrantes indocumentados, solicitantes de asilo y refugiados se están abordando en términos de un asunto de justicia penal. Por lo tanto, los cruces de fronteras no autorizados, que en el pasado rara vez fueron sancionados, se han convertido en un delito penal en muchos países; de manera similar, el número de delitos cometidos por extranjeros y castigados con la deportación ha aumentado considerablemente; finalmente, con la guerra global contra el terror, los no-ciudadanos de diferentes países occidentales han sido detenidos y deportados por sus presuntos vínculos con el terrorismo ${ }^{104}$. Esta continua fusión entre el derecho de la inmigración y el derecho penal ha dado lugar al fenómeno de la crimigración. Si bien el fenómeno representa un desarrollo clave en los procesos de exclusión de inmigrantes indocumentados, debemos no obstante observar que la crimigración es un fenómeno que se encuentra en el límite de las estrategias sociopolíticas de exclusión ya que, de hecho, significa un paso decisivo en la esfera de la exclusión jurídica (que ha sido objeto de análisis en la sección anterior del artículo) ${ }^{105}$.

Ahora paso brevemente a la "estrategia de contaminación". La esencia de este enfoque, al menos en esta versión, es el empleo de la analogía entre la población de un Estado-nación y el cuerpo humano; para comparar

${ }^{104}$ Véase Stumpf, J., “The Crimmigration Crisis: Immigrants, Crime, and Sovereign Power", American University Law Review, 56, 2, 2006, pp.379 y ss.

${ }^{105}$ Véase más arriba, 3.1. La llamada crimigración (criminalización de la migración) se ha convertido en los últimos años en uno de los temas más discutidos en estudios socio-jurídicos, criminología, estudios de migración, etc. Véase, por ejemplo: Stumpf, J., op. cit:; Franko Aas, K, 'CCrimmigrant' bodies and bona fide travellers: Surveillance, citizenship and global governance", Theoretical Criminology, 15, 3, 2011, pp. 331-346; Franko Aas, K. and Bosworth, M. (eds), The Borders of Punishment: Migration, citizenship and social exclusion ( $1^{\text {st }}$ ed.), Oxford, Oxford University Press, 2013; Gerard, A. y Pickering, S., "Crimmigration. Criminal justice, refugee protection and the securitisation of migration”, en Arrigo, B.A. y Bersot, H.Y. (eds.), The Routledge Handbook of International Crime and Justice Studies, Abingdon, Routledge, pp. 587-611; García Hernández, C.C., Crimmigration Law, Chicago, American Bar Association, 2015. 
¿Por quién doblan las campanas del Derecho? Sobre la exclusión jurídica...

el impacto de los inmigrantes en la nación con el de una enfermedad (o un veneno o suciedad) que afecta la salud del cuerpo humano ${ }^{106}$. En su libro, Barsky plantea un paralelo entre los acontecimientos de la historia literaria y la retórica antiinmigrante de hoy. Barsky demuestra cómo en los juicios del siglo XIX contra Flaubert, Baudelaire y Zola, estos famosos autores fueron procesados porque en ese momento las autoridades consideraban que sus obras eran obscenas y, como tales, representaban un peligro inminente para la salud de la nación. Barsky señala que Les Fleurs $d u$ mal de Baudelaire fue "denunciada como repugnante hasta el punto de causar una especie de infección" ${ }^{107}$. El hecho de que se hicieran las mismas acusaciones contra Henry Vizetelly, el traductor de las obras de Zola al inglés, es particularmente significativo para nuestro caso, ya que, desde un punto de vista simbólico, estas traducciones fueron vistas como un intento de introducir en el cuerpo político nacional algo sucio o infeccioso ${ }^{108}$. A diferencia del caso anterior, aquí la amenaza es externa, es decir, extranjera tanto lingüística como moral y existencialmente ${ }^{109}$. Considerada como una amenaza para la integridad del cuerpo, su introducción debía evitarse a toda costa. En este punto, la analogía con la forma en que actualmente los inmigrantes son a menudo representados en el discurso público parece clara: llamándolos insectos, violadores, fundamentalistas musulmanes, etc., el objetivo es que parezcan una amenaza existencial para nuestra forma de vida (nuestros valores morales, idioma, religión, etc.) y, por lo tanto, que deba prohibírseles el acceso o, si ya están infiltrados, aislarlos y luego retirarlos del cuerpo político, antes de que la infección que representan se extienda a través del cuerpo que los recibió.

${ }^{106} \mathrm{La}$ analogía entre la nación y el cuerpo humano es común, especialmente en referencia a la filosofía política medieval, y encuentra su expresión más famosa en la metáfora del cuerpo político. Véase, por ejemplo: Thomas Hobbes' Leviathan (1651) y el estudio clásico de Kantorowicz sobre la teología política medieval: King’s Two Bodies (1957).

${ }^{107}$ Barsky, R., op. cit., p. 50.

${ }^{108}$ Ibidem, p. 51.

${ }^{109}$ Idem. 
Matija Žgur

\section{El derecho y el lenguaje como, de nuevo, instrumentos de exclusión. El caso de los Borrados en Eslovenia}

En esta parte, presento y analizo el caso que comúnmente se conoce como El Borrador (The Erasure). El propósito de esto es probar la validez de las tesis y la utilidad de la metodología propuesta en la parte anterior de este artículo. Si bien los dos casos difieren en varias maneras ${ }^{110}$, propongo que también comparten muchas características relevantes, en particular las relacionadas con las características de los mecanismos de exclusión empleados, lo que hace que el caso El Borrador sea adecuado como test. Así, en la primera sección (4.1.), presento brevemente los antecedentes y hechos relevantes del caso. A continuación, reproduzco la estructura de la parte precedente y, luego, en la siguiente sección (4.2.), analizo los mecanismos de exclusión jurídica empleados en este caso, mientras que en la sección final (4.3.), señalo los mecanismos correspondientes a la exclusión social.

\subsection{Construir una nación sobre la espalda de otros (Brevemente sobre los antecedentes y hechos del caso)}

El Borrador fue un acto administrativo realizado por las autoridades estatales eslovenas a principios de 1992, por medio del cual más de 25.000 personas, residentes en Eslovenia, pero provenientes de otras antiguas repúblicas de la República Federal Socialista de Yugoslavia (RFSY), fueron privadas de su condición de residentes permanentes en Eslovenia. $\mathrm{Su}$ eliminación de los registros de residentes permanentes (El Borrador en sentido estricto) fue parte de un proyecto de exclusión más amplio dirigido contra aquellos ciudadanos de la RFSY que no estaban dispuestos a o no

\footnotetext{
${ }^{110} \mathrm{La}$ diferencia clave es que antes de El Borrador, los individuos en cuestión eran residentes legales de Eslovenia. Además, en el período crucial ya estaban en territorio esloveno. Por otro lado, la mayoría de los inmigrantes indocumentados intentan ingresar a un país en particular, por lo que son calificados de ilegales en el momento en que intentan cruzar la frontera.
} 
¿Por quién doblan las campanas del Derecho? Sobre la exclusión jurídica...

podían obtener la ciudadanía de la nueva Eslovenia independiente, después de su separación de la RFSY en 1991. (El Borrador en sentido amplio) ${ }^{111}$.

En el proceso El Borrador en sentido amplio, quienes eventualmente fueron borrados del registro de residentes permanentes perdieron, ante todo, la ciudadanía eslovena. Sin embargo, aunque la mayoría de estas personas renunciaron voluntariamente a la posibilidad de obtenerla (ya que no la solicitaron cuando se les presentó la posibilidad), el hecho es que muchos de ellos también se quedaron sin ninguna otra ciudadanía, y por lo tanto se convirtieron en apátridas de iure, o fueron, por diversas razones, incapaces de demostrar que eran ciudadanos de otro país y, por lo tanto, se convirtieron en apátridas de facto ${ }^{112}$. Al ser privados también de su estatus de residencia, quedaron sin ninguna base jurídica válida para residir en territorio esloveno. Después de años, incluso décadas, de ser residentes legales en Eslovenia, su presencia en el territorio se volvió de repente ilegal. En consecuencia, fueron expuestos a diferentes sanciones administrativas, encarcelamiento e incluso expulsión ${ }^{113}$. Además, viendo cómo la mayoría de los derechos socioeconómicos estaban condicionados al estatus de residente, los borrados también perdieron derechos y servicios tales como los derechos de seguro de salud básico, el derecho al trabajo, las prestaciones por desempleo, etc. ${ }^{114}$. En términos prácticos, el hecho de haber sido borrado significaba que no podían entrar ni salir del país; ni

${ }^{111}$ Para un análisis de la secesión de Eslovenia a la luz de los cambios geopolíticos globales de la época, véase Villa, C.G., Un Nuevo Estado para un Nuevo Orden Mundial: Una (re) Lectura del Proceso Soberanista Esloveno, Tesis de doctorado, Madrid, Universidad Complutense de Madrid, 2014 (defendida el 27 de noviembre del 2014).

${ }^{112}$ Las circunstancias complejas y confusas de las leyes de ciudadanía en la ex RFSY y de su implementación práctica, así como las circunstancias del período de separación RFSY deben tomarse en consideración aquí. Sobre esto, véase Kogovšek Šalamon, N., Erased. Citizenship, Residence Rights and the Constitution in Slovenia, Frankfurt am Main-BerlinBern-Bruxelles-New York-Oxford-Wien, Peter Lang, 2016, Parte I, Cap. 1. Véase además Mindus, P., op. cit., pág. 154 y ss.

${ }^{113}$ Cfr. Kogovšek Šalamon, N., op. cit., p. 124 y ss.

${ }^{114}$ Para un análisis exhaustivo de las violaciones de los derechos humanos fundamentales involucrados en El Borrador, véase Kogovšek Šalamon, N., "The erasure as a violation of legally protected human rights”, en Kogovšek Šalamon, N. et al. (eds.), The Scars of Erasure. A Contribution to the Critical Understanding of the Erasure of People from the Register of Permanent Residents of the Republic of Slovenia, Ljubljana, Peace Institute, 2010, pp. 83-144. 
Matija Žgur

probar su identidad en cualquier tipo de procedimiento administrativo; ni obtener o renovar una licencia de conducir o abrir una cuenta bancaria; también implicaba dificultades para mantener un trabajo y un apartamento; obtener tratamiento médico, etc. El Borrador también provocó que las familias se separaran debido a la guerra que se libró en otros estados de la ex RFSY, ya que miembros de una misma familia estaban atrapados en diferentes Estados ${ }^{115}$.

El Tribunal Constitucional de Eslovenia declaró dos veces que $E l$ Borrador era inconstitucional: primero en $1999^{116}$, y luego nuevamente en $2003^{117}$, cuando también ordenó al Gobierno que comenzara a hacerse cargo de los borrados, estableciendo su estatus de residencia permanente desde el día en que fueron borrados (ex tunc). Esta última decisión no se implementó sino hasta principios de 2008. Mientras tanto, se presentó una queja ante el Tribunal Europeo de Derechos Humanos, que resultó en la decisión de la Gran Cámara de 2012 de condenar a Eslovenia por violación del derecho de los solicitantes a la vida privada y familiar, del derecho a un recurso efectivo y de la prohibición de discriminación, entre otros ${ }^{118}$. Después, la mayoría de los borrados pudieron obtener algún tipo de alivio, aunque para muchos de ellos los efectos de El Borrador fueron irreversibles, e incluso quedan todavía algunos casos sin una adecuada resolución hasta el día de hoy ${ }^{119}$.

${ }^{115}$ Varios relatos sobre las historias de personas borradas de los registros de ciudadanía se ensamblan en Kogovšek Šalamon, N. et al., op. cit.

${ }^{116}$ Véase la decisión U-I-284/94 del Tribunal Constitucional, del 4 de febrero de 1999. Nótese que la solicitud de revisión de la constitucionalidad de la ley atacada se presentó en 1994, pero solo se resolvió en 1999.

${ }^{117}$ Véase la decisión U-I-245/02 del Tribunal Constitucional, de 3 de abril de 2003.

${ }^{118}$ Véase el caso Kurić y otros v. Eslovenia, solicitud no. 26828/06 (sentencia de Gran Sala de 26 de junio de 2012).

${ }^{119}$ Para un análisis extenso de todas las decisiones judiciales relevantes en este caso, véase Kogovšek Šalamon, N., Erased, op. cit., Parte V. Para un análisis de los problemas pendientes, véase Kogovšek Šalamon, N., "Constitutional Democracy and the Problem of Erasure from the Registry of Permanent Residents: Challenges and Perspectives" en Žgur, M., Kogovšek Šalamon, N. y Koritnik, B. (eds.), Constitutional Law Challenges in the 21st Century. Liber amicorum Ciril Ribičič, Maribor, Institute for Local Self-Government and Public Procurement, 2017, pp. 155-168. 
¿Por quién doblan las campanas del Derecho? Sobre la exclusión jurídica...

\subsection{Creación de personas ilegales: El Borrador en sentido estricto}

Antes de la disolución de la RFSY en 1991, sus ciudadanos tenían doble ciudadanía: la de la federación y la de una de sus repúblicas. Dado que la primera ciudadanía garantizaba la igualdad de derechos con la población indígena en cualquiera de las repúblicas, muchos ciudadanos yugoslavos establecieron su residencia (permanente) en una república diferente de la de origen ${ }^{120}$. Después de la secesión de Yugoslavia en junio de 1991, Eslovenia se propuso establecer inmediatamente una nueva política de ciudadanía. Si bien a los ciudadanos eslovenos se les otorgó automáticamente la ciudadanía del nuevo Estado independiente, una ley constitucional ${ }^{121}$ estipulaba que los ciudadanos de otras repúblicas de la RFSY, que tenían residencia permanente en Eslovenia (y que al día del referéndum de independencia realmente vivían allí ${ }^{122}$ ), tenían los mismos derechos y obligaciones que los ciudadanos eslovenos, al menos hasta que obtuvieron la ciudadanía eslovena ${ }^{123}$ o hasta que el plazo para su adquisición expirara.

${ }^{120}$ En el momento de la independencia de Eslovenia, aproximadamente 200.000 ciudadanos de otras repúblicas de la RFSY residían permanentemente en Eslovenia, lo que representa aproximadamente el $10 \%$ de la población total. Sobre la regulación de la ciudadanía en la ex RFSY, véase Kogovšek Šalamon, N., Erased, op. cit., parte I, cap. 1.

${ }^{121}$ The Constitutional Act Implementing the Basic Constitutional Charter on the Independence and Sovereignty of the Republic of Slovenia, Official Gazette of the Republic of Slovenia, No. 1/1991-I.

${ }^{122}$ El referéndum sobre la independencia de Eslovenia (el plebiscito) se celebró el 23 de diciembre de 1990. La Ley sobre su aplicación (el Referendum on the Sovereignty and Independence of the Republic of Slovenia Act, Official Gazette of the Republic of Slovenia, No. 44/90) determinó que todos los adultos con residencia permanente en Eslovenia el día del referéndum eran electores, incluidos los nacionales de otras repúblicas de la RFSY con residencia permanente en Eslovenia. Al permitir que los ciudadanos de estas repúblicas voten en el referéndum constitutivo del Estado, el Estado esloveno demostró, tanto jurídica como simbólicamente, que los percibía como miembros constituyentes de su (nuevo) cuerpo político. Sobre la inclusión y exclusión de los no nacionales de la participación política plena, véase Mindus, P., "Citizenship and Arbitrary Law-Making: On the Quaintness of Non-national Disenfranchisement", Società Mutamento Politica, 7, 13, 2016, pp. 103-118.

${ }^{123}$ Las condiciones para la adquisición de la ciudadanía se determinaron en el art. 40 de la Ley de ciudadanía (Official Gazette of the Republic of Slovenia, No. 1/1991-I). Esta legislación determinaba que los ciudadanos de las antiguas repúblicas de la RFSY que no eran ciuda- 
Matija Žgur

Las bases jurídicas de El Borrador se establecieron en el párrafo 2, art. 81 de la Ley de Extranjería. Allí se estableció que trascurridos dos meses de la expiración de la fecha límite para la adquisición de la ciudadanía (o dos meses después de haber recibido una decisión final negativa al respecto), las disposiciones de esta ley comenzarían a aplicarse para aquellas personas que no hubiesen solicitado la ciudadanía a tiempo o para aquellos cuyas sus solicitudes fuesen denegadas. Se reconoce ampliamente que esta disposición era tan ambigua que dejó a los afectados en una posición jurídica incierta ${ }^{124}$. Una interpretación a priori razonable de esta disposición era que, a partir del plazo establecido, estas personas serían tratadas de la misma manera que otros extranjeros no yugoslavos que obtuvieron el estatus de extranjero bajo las leyes yugoslavas, aunque residiesen permanentemente en Eslovenia. Sin embargo, lo que establecía el párrafo 3, art. 82 de la misma ley de extranjería era algo distinto: en él se establecía claramente que los permisos de residencia permanente otorgados a estas personas según la ley yugoslava seguían siendo válidos incluso con la aplicación de la nueva ley de extranjería ${ }^{125}$. Frente a esta variedad de posibles interpretaciones de la disposición en disputa, el Ministerio de Asuntos Interiores, que tenía la autoridad para supervisar la implementación de la legislación de ciudadanía, estableció su propia interpretación, particularmente restrictiva, de dicha disposición. Para asegurar una aplicación uniforme de esta ambigua disposición (y de otros actos legales relevantes) en todo el país, el Ministerio emitió una serie de instrucciones, no publicadas, a los

danos de Eslovenia podían adquirir la ciudadanía eslovena si cumplían con tres requisitos: i) habían adquirido la residencia permanente en Eslovenia antes del 23 de diciembre de 1990 (fecha del referendum); ii) residían realmente en Eslovenia, y iii) habían solicitado la ciudadanía dentro de los seis meses posteriores a la entrada en vigor de la Ley de ciudadanía.

${ }^{124}$ Como argumenta Kogovšek Šalamon: "No estaba claro qué se esperaba, si es que se esperaba algo, de los ciudadanos de otras repúblicas de la RFSY que no obtuvieron la ciudadanía eslovena. No estaba claro si tenían que hacer algo para conservar su estatus jurídico, o si no tenían que hacer nada porque su estatus se regularía automáticamente" (Kogovšek Šalamon, N., Erased, op. cit., p. 95).

${ }^{125}$ Este tratamiento diferenciado no tenía una base racional y representaba una discriminación del grupo de extranjeros afectados (es decir, nacionales de otras repúblicas de la RFSY) de acuerdo con el Tribunal Europeo de Derechos Humanos. Véase la decisión Kurić, párrafos 391 y 392. 
¿Por quién doblan las campanas del Derecho? Sobre la exclusión jurídica...

órganos administrativos locales encargados de ejecutar estas normas. Allí, el Ministerio explicó el carácter vinculante de su interpretación sobre la disposición en cuestión y detalló qué medidas debían tomarse para implementar adecuadamente esta política.

En su instrucción del 27 de febrero de 1992 (un día después de la expiración del plazo legal para la adquisición de la ciudadanía), el Ministerio determinó que después de la entrada en vigor de la Ley de Extranjería con respecto a este grupo de personas, había que regular su nuevo estatus. Simultáneamente, la instrucción estableció que se llevara a cabo la limpieza de los registros (de residentes permanentes). Con este fraseo, el Ministerio dispuso efectivamente El Borrador ${ }^{126}$. En su segundo párrafo, la instrucción además explicó que cualquier documento, incluso si había sido emitido por las autoridades competentes eslovenas y poseía todavía con validez formal, dejaría de ser válido dado el cambio en su estatus de estas personas ${ }^{127}$.

Un examen crítico de los actos jurídicos relevantes y las acciones oficiales muestra que se ejerció una arbitrariedad maliciosa en diferentes etapas del proceso. En primer lugar, se ha demostrado de manera convincente que la adopción de disposiciones vagas y ambiguas en la ley de extranjería fue un acto deliberado del legislador, quien anticipó y deseó las consecuencias de ese proceso ${ }^{128}$. Incapaz de adoptar una norma explícitamente excluyente, el legislador recurrió en cambio a una solución mediante la cual delegó implícitamente los poderes legislativos a la rama ejecutiva ${ }^{129}$. $\mathrm{Al}$ permitir que agentes ejecutivos tuvieran poderes legislativos amplios $\mathrm{y}$ no controlados, el legislador aumentó enormemente la posibilidad de que estos poderes se ejercieran de manera arbitraria y, por lo tanto, que violaran

${ }^{126}$ Para un análisis más detallado de esta Instrucción, véase Kogovšek Šalamon, N., Erased, op. cit., p. 105 y ss.

${ }^{127}$ En una Instrucción posterior, a partir de junio de 1992, el Ministerio determinó explícitamente que si tales individuos todavía estaban en posesión de una tarjeta de identificación emitida por la República de Eslovenia, la tarjeta debía ser destruida.

${ }^{128}$ Véase Kogovšek Šalamon, N., Erased, op. cit., pp. 98-101.

${ }^{129}$ Véase Richardson, quien argumenta que tal delegación se produce cuando se sanciona una legislación "vaga e inconclusa", que "deja como única opción a las [agencias gubernativas] la de decidir sobre cuestiones políticas de gran alcance" Richardson, H., "Administrative Policy-making: Rule of Law or Bureaucracy?", en Dyzenhaus, D. (ed.), Recrafting the Rule of Law: The Limits of Legal Order, Oxford \&Portland (Or.), Hart Publishing, 1999, pág. 311. 
Matija Žgur

las exigencias del Estado de derecho ${ }^{130}$. En segundo lugar, El Borrador se realizó en secreto, a través de actos ejecutivos no publicados, únicamente con ciertos funcionarios gubernamentales conscientes de lo que se estaba haciendo. Tampoco se dio aviso a los individuos afectados sobre lo que podría ocurrir, ni se les notificó del cambio en su estado jurídico ex post facto. No es necesario enfatizar cómo las acciones oficiales que infringen los derechos de los individuos y no se basan en leyes de acceso público constituyen una clara violación del principio de legalidad (y especialmente del ideal del Estado de derecho) ${ }^{131}$. En El Borrador, esta violación fue exacerbada por la magnitud y la intensidad del caso. Como señala Rangelov, "el hecho de que la medida haya sido implementada por medio de una decisión ejecutiva mantenida en secreto ... exacerbó la vulnerabilidad de los borrados, exponiéndolos a la arbitrariedad y al abuso de poder por parte de los agentes del Estado"132. Esto nos conduce al punto final. Fue precisamente en virtud del carácter secreto de El Borrador y, como consecuencia, de la falta de familiaridad con sus consecuencias, que los Borrados vivieron expuestos constantemente a consecuencias impredecibles en sus interacciones con los funcionarios públicos. Especialmente en las comunidades más pequeñas, donde los funcionarios encargados de hacer cumplir la ley conocían personalmente a estas personas y podían, en un momento dado y sin ninguna sospecha particular, detenerlos en medio de la carretera o indagar sobre su condición de residencia. A partir de ese momento, se pueden producir numerosas consecuencias: desde una simple palmada en la espalda hasta un acoso desagradable en mayor o en menor medida; desde la emisión de una sanción administrativa por no poseer documentos válidos, hasta el encarcelamiento y la deportación ${ }^{133}$.

${ }^{130}$ Endicott, T., “The Impossibility of the Rule of Law”, Oxford Journal of Legal Studies, 19, 1, 1999, pp. 1-18. Sobre este argumento, véase supra, 3.1.

${ }^{131}$ Sobre este argumento, véase Kutz, C., "Secret Law and the Value of Publicity", Ratio Juris, 22, 2, 2009, pp. 197-217.

${ }^{132}$ Rangelov, I., Nationalism and the rule of law. Lessons from the Balkans and beyond, New York, Cambridge University Press, 2014, p. 106.

${ }^{133}$ Un ejemplo paradigmático de dicha aplicación arbitraria de la ley es la historia de Rifet, que vivía en una pequeña ciudad eslovena y fue detenido repetidamente por agentes de la policía local, ya que sabían que no poseía ningún documento válido. Rifet fue en múltiples ocasiones acosado y golpeado por los oficiales de policía. En una de esas ocasiones fue tan 
¿Por quién doblan las campanas del Derecho? Sobre la exclusión jurídica...

\section{3. "Los sureños" como el Otro significativo}

La eliminación de los registros administrativos fue solo una parte (aunque fundamental) del proceso de El Borrador en sentido amplio, que incluyó una serie de acciones por parte de las autoridades eslovenas previas e inmediatamente después de la separación eslovena de la RFSY, y que dio lugar a la exclusión más o menos exhaustiva de un conjunto particular de individuos del nuevo cuerpo político esloveno.

Siguiendo el enfoque metodológico propuesto anteriormente (véase el apartado 3.2.), El Borrador en sentido amplio puede analizarse como un proceso de Otredad dentro de una población en al menos una de dos maneras (o en ambas): (i) presentando a una población específica como una amenaza de seguridad (la estrategia de seguritización) o (ii) presentando a una población específica como un peligroso contaminante (la estrategia de contaminación). En este caso, sostengo que la estrategia de Otredad empleada de manera predominante fue la segunda, aunque es posible identificar elementos de la estrategia de seguritización en algunos actos de las autoridades eslovenas ${ }^{134}$. Este hecho pudo contribuir a la naturaleza del proceso de autoidentificación nacional, que en este caso se basó en la identidad cultural eslovena. A la luz de esto, El Borrador en sentido amplio debe entenderse como "parte integral de la construcción de la identidad nacional eslovena en el marco del establecimiento de la soberanía nacional de Eslo-

golpeado que incluso la policía tuvo que reconocer que fue sometido a torturas y tratos inhumanos, ya que iniciaron procedimientos judiciales contra el oficial en cuestión. Ver Kogovšek Šalamon, The erasure as a violation, op. cit., pp. 89-90.

${ }^{134}$ Esto es particularmente evidente con respecto a las personas que fueron incluidas en la llamada lista negra, es decir, una lista de personas a las que se prohibiría la entrada a Eslovenia después de que se independizara y a las que no se les debería otorgar la ciudadanía. La lista incluía en su mayoría a empleados del ejército yugoslavo y ciertas personas sospechosas de oponerse a la independencia de Eslovenia. Para evitar que estas personas obtuvieran la ciudadanía eslovena, el legislador adoptó posteriormente las enmiendas al art. 40 de la Ley de ciudadanía (sobre esto, ver más arriba, 4.2.), que contenía (en el párrafo 3, Art. 40) una cláusula de exclusión que permitía rechazar la ciudadanía a personas que representaban una amenaza para el orden público, la seguridad y la defensa del Estado. Para más información sobre esta cláusula de exclusión, que más tarde fue parcialmente declarada inconstitucional, véase Kogovšek Šalamon, N., Erased, op. cit., pp. 75 y ss. 
venia"135, que surgió principalmente a través de un proceso de depuración (simbólica y jurídico-política) del cuerpo nacional esloveno, eliminando la presencia contaminante de Otros en la forma de los "sureños"136.

La construcción de una identidad nacional, tan fundamental en el proceso de establecer un nuevo Estado-nación, es en su núcleo un proceso relacional. Esto se debe a que la identidad nacional no tiene un significado objetivo por sí mismo, sino que "su existencia presupone la presencia de Otros, otras naciones u otros individuos, que no pertenecen al grupo interno y de los cuales el grupo externo debe ser distinguido"137. Por lo tanto, si bien la autoidentificación emerge a través de ciertos elementos autónomos que definen a la nación, por ejemplo, la creencia en una ascendencia o cultura en común, el apego a un territorio específico, etc., ninguno de estos elementos es una condición necesaria a priori para establecer una identidad nacional. Cuál de estos elementos finalmente se vuelve relevante para constituir la identidad nacional, "depende de las características o los reclamos de otros grupos de los cuales la nación busca diferenciarse"138. Triandafyllidou denomina a tales grupos como Otros significativos y son presentados típicamente como una amenaza para la nación y su identidad ${ }^{139}$.

En nuestro ejemplo, se puede decir que los Otros significativos estaban compuestos por ciudadanos de otras naciones yugoslavas que residían permanentemente en Eslovenia durante el período crucial de secesión. El punto central de la distinción entre nosotros y ellos, es decir, el elemento clave que define a la nación y que, al mismo tiempo, es presentado como

${ }^{135}$ Bajt, V., "More than administratively created 'foreigners': the erased people and a reflection of the nationalist construction of the Other in the symbolic idea about 'us"', en Kogovšek Šalamon, N. et al. (eds.), The Scars of Erasure. A Contribution to the Critical Understanding of the Erasure of People from the Register of Permanent Residents of the Republic of Slovenia, Ljubljana, Peace Institute, 2010, pág. 196.

${ }^{136}$ Esta expresión ha sido ampliamente utilizada en Eslovenia con un significado peyorativo para hacer referencia a los ciudadanos de otras repúblicas de la RFSY, resonando la idea de que los que vienen del sur son, de alguna manera, peores, menos trabajadores, vividores, etc.

${ }^{137}$ Triandafyllidou, A., "National identity and the 'other", Ethnic and Racial Studies, 21, 4, 1998, p. 599.

${ }^{138} \mathrm{Idem}$.

139 "La noción de un otro significativo se refiere a otra nación o grupo étnico que está territorialmente cerca de la comunidad nacional, o incluso dentro de ella, y amenaza, o más bien se percibe que amenaza, su pureza étnica y/o cultural y/o su independencia”. (Ibidem, p. 600). 
¿Por quién doblan las campanas del Derecho? Sobre la exclusión jurídica...

el valor fundamental que los otros ponen en peligro, lo constituyeron la cultura y el idioma autóctonos de Eslovenia. Aunque la consolidación del nacionalismo esloveno comenzó a principios del siglo XIX, se hizo particularmente poderoso con el surgimiento del movimiento cultural-literario de 1980, que puso especial énfasis en el problema de la lengua eslovena como el elemento clave de la identidad eslovena y que estaba siendo reprimido en el contexto de la RFSY ${ }^{140}$. De este modo, este movimiento dio origen a las primeras "demandas de autonomía cultural-lingüística, bien articuladas, que se creían imposibles de alcanzar sin la soberanía política"141.

Desde esta perspectiva, El Borrador se puede entender como una especie de sanción contra aquellos que no se sometieron voluntariamente a la asimilación cultural eslovena obteniendo dicha ciudadanía. Con la nueva política de ciudadanía eslovena, definida étnicamente y nacionalista en su núcleo ${ }^{142}$, la generosa oferta extendida a las personas no eslovenas para obtener esta ciudadanía puede verse como un intento del Estado por asimilar a los Otros potenciales “a través de una homogenización (más o menos) forzada de la comunidad nacional dentro de los límites de un estado-nación" ${ }^{143}$. Mientras que aquellos que obtuvieron la ciudadanía fueron bienvenidos en el nuevo cuerpo político, aquellos que no quisieron renunciar a otras lealtades (políticas y culturales) y, al menos simbólicamente, adoptar la identidad eslovena como su identidad principal, fueron inmediatamente calificados como traidores y enemigos del Estado ${ }^{144}$. En el siguiente paso, dado el vínculo inherente construido entre el Estado esloveno y la nación

${ }^{140}$ En este contexto, el tipo de nacionalismo esloveno está señalado como etnonacionalismo. Véase Bajt, V., op. cit., pág. 205 y ss.; Zorn, J., "We, the Ethno-citizens of Ethno-democracy - The Formation of Slovene Citizenship", Journal for the Critique of Science, 35, 228, 2007, pág. 55 y ss.; Rangelov, op.cit., pág. 122 y ss.

${ }^{141}$ Zorn, J., op. cit., p. 55.

${ }^{142}$ En general sobre ciudadanía étnica, véase Rangelov, I., op. cit., I, cap. 1; para el caso específico de la ciudadanía étnica eslovena, véase Ibidem, parte II, cap. 4. Sobre la noción de democracia étnica, véase Smooha, S., "The Model of Ethnic Democracy”, ECMI Working Paper n. 13, Flensburg, 2001.

${ }^{143}$ Bajt, V., op. cit., p. 199.

${ }^{144}$ Véase Bajt, V., op. cit., p. 197; Jalušič, V., “Organized Innocence”, en Dedić, J., Jalušič, V., y Zorn, J. (Eds.), The Erased. Organized Innocence and the Politics of Exclusion, Ljubljana, Peace Institute, 2003, p. 8. 
Matija Žgur

constitutiva únicamente de eslovenos, aquellos que no eran identificables como verdaderos eslovenos a través del factor de identificación clave (es decir, de la ciudadanía eslovena), "tenían que ser excluidos de la pertenencia nacional y del Estado, ya que, de acuerdo con la doctrina nacionalista que subordina todas las pertenencias e identidades a la nación eslovena, fueron definidos como otros, como cuerpos extraños en el organismo nacional, que debían eliminarse. Literalmente tenían que ser borrados"145.

\section{Conclusión}

En la novela El barco de la muerte, B. Traven cuenta la historia de un marinero estadounidense que deambula por el mundo después de haber perdido su pasaporte. El relato realista de Traven sobre los sufrimientos cotidianos del protagonista emanados de ser indocumentado (apátrida), confirma la caracterización que hace Bauman de tales individuos como desechos humanos. Sin ningún medio para demostrar su estatus como ciudadano estadounidense, Gerard ingresa al mundo de la marginación social y la imprevisibilidad jurídica. Obligado a trabajar ilegalmente en un barco deteriorado y a confiar en la amabilidad de los extraños para obtener comida y alojamiento, Gerard es la personificación de los oprimidos socialmente. Como extranjero ilegal, una vez detenido por las fuerzas policiales de cualquier país en el que se encuentre, está totalmente expuesto a los caprichos de los funcionarios, que lo someten a hostigamientos, interrogatorios prolongados, encarcelamientos repetidos y deportación. Todo esto no por haber cometido un delito particular, sino por ser la encarnación de la ilegalidad.

En este artículo, busqué probar las tesis de Robert Barsky sobre la difícil situación de los inmigrantes indocumentados en sus sociedades de acogida.

${ }^{145}$ Bajt, V., op. cit., p. 213. Bajt también señala acertadamente la "naturaleza esquizofrénica del nacionalismo esloveno" en que "aunque todos los elementos esenciales de la identidad nacional eslovena pueden ser 'adquiridos' (el lenguaje es el mejor ejemplo), lo que significa que en su esencia son potencialmente de naturaleza cívica; sin embargo, los extranjeros nunca son verdaderamente reconocidos como verdaderos eslovenos, porque la idea de eslovenidad todavía es arcaicamente étnica”. (Ibidem, p. 206). 
Así, analicé la naturaleza y el papel de la aplicación arbitraria de la ley por parte de los funcionarios de la primera línea. Esa arbitrariedad posiblemente sea la característica clave de las interacciones entre los primeros y los inmigrantes indocumentados. Tomé las afirmaciones de Barsky con respecto al papel que los discursos sociales excluyentes sobre los inmigrantes indocumentados desempeñan en la producción de su vulnerabilidad jurídica y social, y analicé dos estrategias de exclusión social. Para probar la tesis según la cual los mecanismos jurídicos y sociales de exclusión no son paralelos entre sí, sino que en los casos que involucran a inmigrantes indocumentados se refuerzan y se legitiman mutuamente, presenté el caso de los Borrados, personas que fueron despojadas de su estatus de residentes después de la secesión eslovena de Yugoslavia. El análisis de los mecanismos jurídicos y sociopolíticos que borraron a ese conjunto de personas confirmó las tesis de Barsky tanto sobre la naturaleza de los mecanismos de exclusión en cuanto tales como sobre sus interacciones mutuas. El análisis jurídico y sociopolítico en dos niveles, centrado en las prácticas discursivas en los países de acogida, propuesto por Barsky y probado en el caso de El Borrador, resultó no solo útil para comprender las complejidades de estos procesos sociales, sino que resultó esencial para ello. Ese análisis demostró de manera bastante convincente que las medidas jurídicas y sociopolíticas de exclusión no solo se complementan entre sí, sino que también se legitiman socialmente entre sí y, por lo tanto, refuerzan los efectos excluyentes de cada uno.

(Traducción de Milton Jair Rocha Mendoza, revisada por Revista Discusiones) 
Matija Žgur

\section{Bibliografía}

Alexy, R., A Theory of Legal Argumentation. The Theory of Rational Discourse as Theory of Legal Justification, Oxford, Oxford University Press, 2009 [1989].

Allen, Carleton K., "Status and Capacity”, Law Quarterly Review, CLXXXIII, 1930, pp. 277-310.

Atak, I., Nakache, D., Guild, E. y Crépeau, F., Migrants in vulnerable situations and the Global Compact for Safe Orderly and Regular Migration. Jurídico Studies Research Paper No. 273/2018, Queen Mary University of London, School of Law, 2018.

Austin, J., Lectures on Jurisprudence, or The Philosophy of Positive Law ( $4^{\text {th }}$ ed.), London, John Murray, 2002 [1879].

Bajt, V., "More than administratively created 'foreigners': the erased people and a reflection of the nationalist construction of the Other in the symbolic idea about 'us', en Kogovšek Šalamon, N. et al. (eds.), The Scars of Erasure. A Contribution to the Critical Understanding of the Erasure of People from the Register of Permanent Residents of the Republic of Slovenia, Ljubljana, Peace Institute, 2010, pp. 195-218.

Balzacq, T., "The Three Faces of Securitization: Political Agency, Audience and Context", European Journal of International Relations, 11, 2, 2005, pp. 171-201.

Barsky, R.F., Undocumented Immigrants in an Era of Arbitrary Law. The Flight and the Plight of People Deemed "Ilegal", Oxon-London, Routledge, 2016.

Bauman, Z., Wasted Lives. Modernity and its Outcasts, Cambridge, Polity Press, 2017 [2004].

Baumgartner, F., Epp, D. y Shoub, K., Suspect Citizens. What 20 Million Traffic Stops Tell Us about Policing and Race, Cambridge University Press, Cambridge, 2018.

Bigo, D., "Security and Immigration: Towards a Critique of the Governmentality of Unease”, Alternatives, 27, 2002, pp. 63-92.

Borjas, G., The Labor Supply of Undocumented Immigrants, Working Paper 22102, Cambridge (MA), National Bureau of Economic Research, 2016. 
¿Por quién doblan las campanas del Derecho? Sobre la exclusión jurídica...

Boswell, C. y Straubaar, T., “The Ilegal Employment of Foreign Workers: an Overview", Intereconomics, 39, 1, 2004, pp. 4-7.

Brett, E.A., The World Economy since the War. The Politics of Uneven Development, London, MacMillan, 1985.

Buonfino, A., "Between Unity and Plurality: The Politicization and Securitization of the Discourse on Immigration in Europe", New Political Science, 26, 1, 2004, pp. 23-49.

Buzan, B., Waever, O. y de Wilde, J., Security. A New Framework for Analysis, London, Lynne Rienner Publishers, 1998.

Carter, D.M., State of Grace. Senegalese in Italy and the New European Immigration, London-Minneapolis, University of Minnesota Press, 1997.

Cohen, R., Migration and its Enemies. Global Capital, Migrant Labour and the Nation-State, Aldershot, Ashgate, 2006.

Coulter, A., ¡Adiós, America! The Left's Plan to Turn Our Country into a Third World Hellhole, Washintgon DC, Regnery Publishing, 2015.

Craig, P., "Formal and Substantive Conceptions of the Rule of Law: An Analytical Framework", Public Law, 1997, pp. 467-487.

Dal Lago, A., Non-persone. Lesclusione dei migranti in una società globale ( $5^{\text {th }}$ ed.), Milano, Feltrinelli, 2012 [1999].

Dayan, C., The Law is a White Dog. How Legal Rituals Make and Unmake Persons, New Jersey, Princeton University Press, 2011.

De Genova, N., "Migrant 'Illegality' and Deportability in Everyday Life", Annual Review of Anthropology, 31, 2002, pp. 419-447.

De Schutter, O., Links between migration and discrimination (report for the European Commission), Luxembourg, Publications Office of the European Union, 2009.

Donne, J., “Meditation XVII", Poems, London 1633 [1623].

Dworkin, R., Justice in Robes, Cambridge (Mass.), Harvard University Press, 2006.

Endicott, T., "The Impossibility of the Rule of Law", Oxford Journal of Legal Studies, 19, 1, 1999, pp. 1-18.

Endicott, T., "The Reasons of the Law", The American Journal of Jurisprudence, 48, 2003, pp. 83-106.

Endicott, T., Administrative Law ( $2^{\text {nd }}$ ed.), Oxford, Oxford University Press, 2011. 
Matija Žgur

Endicott, T., "Arbitrariness", Canadian Journal of Law and Jurisprudence, XXXVII, 1, 2014, pp. 49-71.

Fraenkel, E., The Dual State, Clark (N.J.), The Lawbook Exchange, 2010 [1941].

Franko Aas, K., Globalization \& crime, London, SAGE, 2007.

Franko Aas, K., “Crimmigrant' bodies and bona fide travelers: Surveillance, citizenship and global governance", Theoretical Criminology, 15, 3, 2011, pp. 331-346.

Franko Aas, K. y Bosworth, M. (eds), The Borders of Punishment: Migration, citizenship and social exclusion ( $1^{\text {st }}$ ed.), Oxford, Oxford University Press, 2013.

Fuller, L., The Morality of Law (Revised ed.), New Haven-London, Yale University Press, 1969.

García Hernández, C.C., Crimmigration Law, Chicago, American Bar Association, 2015.

Gerard, A. y Pickering, S., "Crimmigration. Criminal justice, refugee protection and the securitisation of migration", en Arrigo, B.A., Bersot, H.Y. (eds.), The Routledge Handbook of International Crime and Justice Studies, Abingdon, Routledge, pp. 587-611.

Goris, I., Jobard, F. y Lévy R., Profiling Minorities: A Study of Stop-andSearch Practices in Paris, New York, Open Society Institute, 2010.

Graveson, R.H., Status in the Common Law, London, University of London (Athlone Press), 1953.

Green, P. y Grewcock, M., “The War against Illegal Immigration: State Crime and the Construction of a European Identity", Current Issues in Criminal Justice, 14, 1, 2002, pp. 87-101.

Guastini, R., Interpretare e argomentare, Milano, Giuffrè, 2011.

Hobbes, T., Leviathan, Oxford, Oxford University Press, 2008 [1651].

Huysmans, J., "The European Union and the Securitization of Migration", Journal of Common Market Studies, 38, 5, 2000, pp. 751-777.

Huysmans, J., The Politics of Insecurity. Fear, migration and asylum in the EU, Abingdon, Routledge, 2006.

Huysmans, J., Dobson, A. y Prokhovnik, R. (eds.), The Politics of Protection. Sites of insecurity and political agency, London-New York, Routledge, 2006. 
¿Por quién doblan las campanas del Derecho? Sobre la exclusión jurídica...

Jalušič, V., “Organized Innocence”, en Dedić, J., Jalušič, V., Zorn, J. (eds.), The Erased. Organized Innocence and the Politics of Exclusion, Ljubljana, Peace Institute, 2003, pp. 7-24.

Jones, R., Violent Borders. Refugees and the Right to Move, London-New York, Verso, 2017.

Johnson, K.R., "The Case Against Race Profiling in Immigration Enforcement”, Washington University Law Quarterly, 78, 3, 2000, pp. 675-736.

Kantorowicz, E., The King's Two Bodies. A Study of Medieval Political Theology, Princeton (NJ), Princeton University Press, 1957.

Knowles, J., Persico, N. y Todd, P., "Racial Bias in Motor Vehicle Searches: Theory and Evidence", Journal of Political Economy, 109, 1, 2001, pp. 203-229.

Kogovšek Šalamon, N., "The erasure as a violation of legally protected human rights", en Kogovšek Šalamon, N. et al. (eds.), The Scars of Erasure. A Contribution to the Critical Understanding of the Erasure of People from the Register of Permanent Residents of the Republic of Slovenia, Ljubljana, Peace Institute, 2010, pp. 83-144.

Kogovšek Šalamon, N., Erased. Citizenship, Residence Rights and the Constitution in Slovenia, Frankfurt am Main, Peter Lang, 2016.

Kogovšek Šalamon, N., "Constitutional Democracy and the Problem of Erasure from the Registry of Permanent Residents: Challenges and Perspectives", en Žgur, M., Kogovšek Šalamon, N., Koritnik, B. (eds.), Constitutional Law Challenges in the 21st Century. Liber amicorum Ciril Ribičič, Institute for Local Self-Government and Public Procurement, Maribor, 2017.155-168.

Kogovšek Šalamon, N. et al. (eds.), The Scars of Erasure. A Contribution to the Critical Understanding of the Erasure of People from the Register of Permanent Residents of the Republic of Slovenia, Ljubljana, Peace Institute, 2010.

Kramer, M., Objectivity and the Rule of Law, Cambridge, Cambridge University Press, 2007.

Kutz, C., "Secret Law and the Value of Publicity", Ratio Juris, 22, 2, 2009, pp. 197-217. 
Matija Žgur

Labman, S., At Law's Border: Unsettling Refugee Resettlement, PhD Thesis, University of British Columbia, defended on 15 November 2012.

Lipsky, M., Street-level Bureaucracy. Dilemmas of the Individual in Public Services, New York, Russell Sage Foundation, 2010 [1970].

MacCormick, N., Rhetoric and the Rule of Law. A Theory of Legal Reasoning, Oxford, Oxford University Press, 2005.

Mackenzie, C., Rogers, W. y Dodds, S., "Introduction: What Is Vulnerability and Why Does It Matter for Moral Theory?", en Rogers, W., Mackenzie, C., Dodds, S. (eds), Vulnerability. New Essays in Ethics and Feminists Philosophy, Oxford, Oxford University Press, 2014, pp. 1-29.

Marglin, S.A. y Schor, J.B. (eds.), The Golden Age of Capitalism. Reinterpreting the Postwar Experience, Oxford, Clarendon Press, 1990.

Marmor, A., "The Rule of Law and Its Limits", Law and Philosophy, 23, 2004, pp. 1-43.

Messina, A., "Securitizing Immigration in the Age of Terror", World Politics, 66, 3, 2014, pp. 530-559.

Miller, J. et al., "Racism and Police Stops. Adapting US and British Debates to Continental Europe", European Journal of Criminology, 5, 2, 2008, pp. 161-191.

Mindus, P., Cittadini e no. Forme e funzioni dell'inclusione e dell'esclusione, Firenze, Firenze University Press, 2014. Hay traducción al español: Hacia una teoría funcionalista de la ciudadanía, Madrid, Marcial Pons, 2019

Mindus, P., "Citizenship and Arbitrary Law-Making: On the Quaintness of Non-national Disenfranchisement", Società Mutamento Politica, 7,13, 2016, pp. 103-118.

Mucchetti, A.E., "Driving while Brown: A Proposal for Ending Racial Profiling in Emerging Latino Communities", Harvard Latino Law Review, 8, 2005, pp. 1-32.

Papastergiadis, N., The Turbulence of Migration. Globalization, Deterritorialization and Hybridity, Cambridge, Polity Press, 2000.

Papayannis, D.M., "Independence, impartiality and neutrality in legal adjudication", Revus - Journal for Constitutional Theory and Philosophy of Law, 28, 2016, pp. 33-52. 
¿Por quién doblan las campanas del Derecho? Sobre la exclusión jurídica...

Plesničar, M.M. and Kukavica, J., "Punishing the Alien: The Sentencing of Foreign Offenders in Slovenia", Dve domovini - Two homelands, 49, 2019, pp. 27-50.

Rangelov, I., Nationalism and the rule of law. Lessons from the Balkans and beyond, New York, Cambridge University Press, 2014.

Raz, J., "The Rule of Law and Its Virtue", Authority of Law. Essays on Law and Morality, Oxford, Oxford University Press, 2009.

Richardson, H. "Administrative Policy-making: Rule of Law or Bureaucracy?", en D. Dyzenhaus, D. (ed.), Recrafting the Rule of Law: The Limits of Legal Order, Oxford -Portland (Or.), Hart Publishing, 1999.

Robertson, R. et al., Working Conditions, Work Outcomes, and Policy in Asian Developing Countries, ADB Economics Working Paper Series (No. 497), Mandaluyong, Asian Development Bank, 2016.

Romero, M., "Racial Profiling and Immigration Law Enforcement: Rounding Up of Usual Suspects in the Latino Community", Critical Sociology, 32, 2-3, 2006, 447-473.

Rothstein, B., Teorell, J., "What Is Quality of Government? A Theory of Impartial Government Institutions", Governance: An International Journal of Policy, Administration, and Institutions, 21, 2, 2008, pp. 165-190.

Salmond, J., Jurisprudence ( $4^{\text {th }}$ ed.), London, Stevens \& Haynes, 1913.

Schauer, F., Thinking Like a Lawyer. A New Introduction to Legal Reasoning, Cambridge (Mass.), Harvard University Press, 2009.

Sindic, D., Morais, R., Costa-Lopes, R., Klein, O., Barreto, M., “Schrodinger's immigrant: The political and strategic use of (contradictory) stereotypical traits about immigrants", Journal of Experimental Social Psychology, 79, 2018, pp. 227-238.

Smooha, S. The Model of Ethnic Democracy, ECMI Working Paper n. 13, Flensburg, 2001.

Sumner Maine, H., Ancient Law, New York, Henry Holt and Co., 1906.

Stumpf, J., "The Crimmigration Crisis: Immigrants, Crime, and Sovereign Power", American University Law Review, 56, 2, 2006, pp. 367-419.

Traven, B., The death ship: the story of an American sailor, New York, Lawrence Hill Books, 1934.

Triandafyllidou, A., "National identity and the 'other", Ethnic and Racial Studies, 21, 4, 1998, pp. 593-612. 
Matija Žgur

Tuzet, G., "A Short Note on Digestive Realism", Revus - Journal for Constitutional Theory and Philosophy of Law, 25, 2015, pp. 11-14.

Ugelvik, T., "The incarceration of foreigners in European prisons", en Pickering, S. and Ham, J. (eds), The Routledge Handbook on Crime and International Migration. London \& New York, Routledge, 2014, pp. 107-120.

Villa, C.G., Un nuevo Estado para un nuevo orden mundial: Una (re) lectura del proceso soberanista esloveno, Tesis de doctorado, Madrid, Universidad Complutense de Madrid, 2014 (defendida el 27 de noviembre de 2014).

Vito, A., Grossi, E., Higgins, G., "The Issue of Racial Profiling in Traffic Stop Citations", Journal of Contemporary Criminal Justice, 33, 3, 2017, pp. 431-450.

Wæver, O., "Securitization and desecuritization", en Lipschutz, R. (eds), On Security, New York, Columbia University Press, 1995, pp. 46-86.

World Bank Group, Moving for Prosperity. Global Migration and Labor Markets, Policy Research Report, Washington, DC, The World Bank, 2018. Wright, G., "Arbitrariness: Why the Most Important Idea in Administrative Law Can't Be Defined, and What This means for the Law in General", University of Richmond Law Review, 44, 2, 2010, pp. 839-865.

Zacka, B., When the State Meets the Street. Public Service and Moral Agency, Cambridge (Mass.)-London, The Belknap Press of Harvard University Press, 2017.

Zorn, J., "We, the Ethno-citizens of Ethno-democracy - The Formation of Slovene Citizenship", Journal for the Critique of Science, 35, 228, 2007, pp. 52-69. 